\title{
Co-operation of TLR4 and raft proteins in LPS-induced pro-inflammatory signaling
}

\author{
Agnieszka Płóciennikowska • Aneta Hromada-Judycka • \\ Kinga Borzęcka $\cdot$ Katarzyna Kwiatkowska
}

Received: 14 July 2014/Revised: 1 October 2014/Accepted: 13 October 2014/Published online: 22 October 2014

(C) The Author(s) 2014. This article is published with open access at Springerlink.com

\begin{abstract}
Toll-like receptor 4 (TLR4) is activated by lipopolysaccharide (LPS), a component of Gram-negative bacteria to induce production of pro-inflammatory mediators aiming at eradication of the bacteria. Dysregulation of the host responses to LPS can lead to a systemic inflammatory condition named sepsis. In a typical scenario, activation of TLR4 is preceded by binding of LPS to CD14 protein anchored in cholesterol- and sphingolipid-rich microdomains of the plasma membrane called rafts. CD14 then transfers the LPS to the TLR4/MD-2 complex which dimerizes and triggers MyD88- and TRIF-dependent production of pro-inflammatory cytokines and type I interferons. The TRIF-dependent signaling is linked with endocytosis of the activated TLR4, which is controlled by CD14. In addition to CD14, other raft proteins like Lyn tyrosine kinase of the Src family, acid sphingomyelinase, CD44, Hsp70, and CD36 participate in the TLR4 signaling triggered by LPS and non-microbial endogenous ligands. In this review, we summarize the current state of the knowledge on the involvement of rafts in TLR4 signaling, with an emphasis on how the raft proteins regulate the TLR4 signaling pathways. CD14-bearing rafts, and possibly CD36-rich rafts, are believed to be preferred sites of the assembly of a multimolecular complex which mediates the endocytosis of activated TLR4.
\end{abstract}

Keywords Lipopolysaccharide · Toll-like receptor 4 . Plasma membrane rafts - CD14 - Lyn tyrosine kinase . Acid sphingomyelinase $\cdot \mathrm{CD} 36$

\footnotetext{
A. Płóciennikowska · A. Hromada-Judycka · K. Borzęcka · K. Kwiatkowska ( $\square)$

Laboratory of Molecular Membrane Biology, Nencki Institute of Experimental Biology, 3 Pasteur St., 02-093 Warsaw, Poland e-mail: k.kwiatkowska@nencki.gov.pl
}

\section{Introduction}

Toll-like receptors (TLRs) recognize a variety of microbial structural components called pathogen-associated molecular patterns (PAMPs). Upon recognition of the PAMPs, TLRs trigger production of pro-inflammatory mediators helping to eradicate infection. Until now, thirteen TLRs have been identified and described in mammals, twelve of which are expressed in mice and ten in humans. The discovery of the role of TLRs has greatly advanced the field of innate immunology and was honored with the Nobel Prize to Jules Hoffmann and Bruce Beutler in 2011. The Beutler's group has revealed that TLR4 is activated by lipopolysaccharide (LPS, endotoxin), a component of the outer membrane of Gramnegative bacteria. LPS is anchored in the bacterial membrane by up to seven acyl chains composing socalled lipid A which is bound to an oligosaccharide core and a highly variable polysaccharide chain named $O$ antigen. Lipid A is the most evolutionarily conserved part of LPS responsible for its pro-inflammatory activity. The maximal potency to trigger inflammation is shown by LPS with a bis-phosphorylated lipid A composed of six saturated acyl chains. The pro-inflammatory action of LPS is crucial for curbing bacterial infections, but excessive host responses to LPS can lead to systemic inflammatory conditions-sepsis, severe sepsis, and fatal septic shock. The incidence of severe sepsis in the European Union has been estimated at 90.4 cases per 100,000 population. In the United States, severe sepsis causes approximately 215,000 deaths per year (nearly as many as lung, colorectal, and breast cancers together). The mortality of severe sepsis reaches 30-50\% worldwide and the absence of efficient therapies makes studies on the molecular mechanisms of activation of cells by 
LPS of utmost importance. Furthermore, the pro-inflammatory activity of TLR4 is linked with pathological responses to endogenous ligands in autoimmune disorders and chronic inflammatory conditions accompanying development of atherosclerosis, neurodegenerative diseases, and others [1-3], which fuels interest in TLR4 signaling.

\section{Activation of TLR4 by LPS}

Since the identification of TLR4 as the LPS receptor in 1998, it has long been assumed to trigger all the responses to LPS $[4,5]$. The receptor is expressed in myeloid lineage cells and some non-immune cells, like intestinal epithelial cells and endothelial cells. It is a single-spanning transmembrane protein with an extracellular domain composed of 22 leucine-rich repeats conferring a horseshoe-like shape on the protein, found typical for TLRs by crystallography studies [6-8]. A transmembrane helix of 21 amino acids links the TLR4 ectodomain with the endodomain of about 200 amino acids, which contains a conserved region called the Toll/ IL-1 receptor (TIR) domain. The TIR domain is critical for signal transduction and is also present in adaptor proteins of TLRs [9].

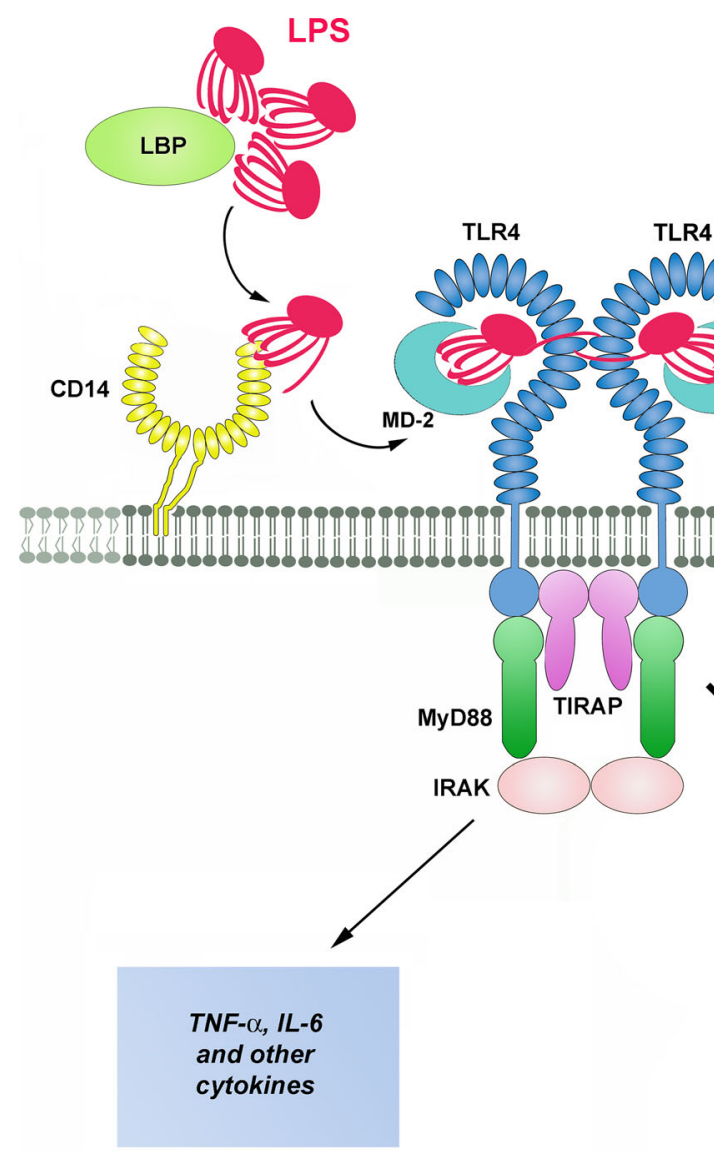

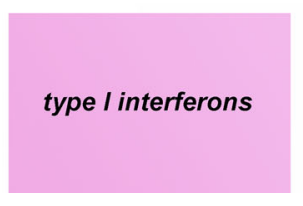

Fig. 1 Activation of TLR4 by LPS. LBP facilitates transfer of LPS monomers to CD14 with the help of LBP and CD14 subsequently shifts the endotoxin to TLR4/MD-2 complex. Dimerization of the receptor complex induces the assembly of TIRAP, MyD88, and IRAK kinases in a myddosome at the TIR domain of TLR4 inducing a signaling pathway raft plasma membrane

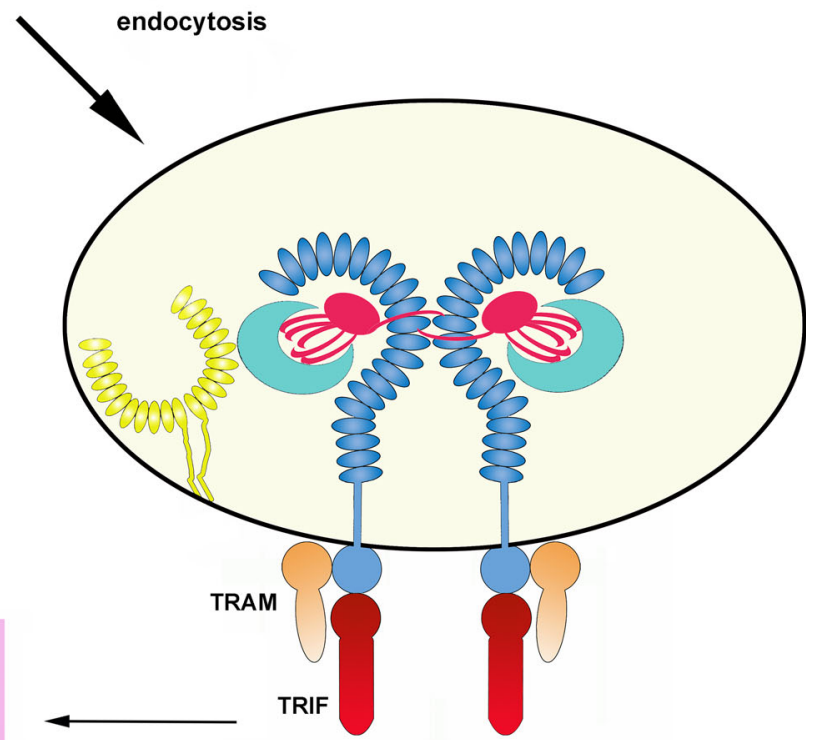

leading to production of pro-inflammatory cytokines. After endocytosis, TRAM and TRIF associate with TLR4 triggering a signaling pathway which controls production of type I interferons and some other cytokines. The presence of leucine-rich repeats in CD14 and TLR4 is marked by ellipses. The molecules are drawn not to scale 
In a typical scenario, activation of TLR4 requires a cascade of events starting from an interaction of LPS with LPS-binding protein (LBP) in the serum (Fig. 1). LBP binds to LPS-rich membranes of bacteria and LPS aggregates (micelles) formed by this amphipatic molecule in aqueous solutions. LBP facilitates extraction of LPS monomers by CD14 protein most likely by changing the arrangement of LPS aggregates [10, 11]. CD14 is a GPIanchored glycoprotein found on the surface of the plasma membrane of monocytes, macrophages, dendritic cells, and at a lower level, neutrophils [12, 13]. It is a horseshoeshaped dimer containing a total of 22 leucine-rich repeats. The main site involved in the binding of LPS (and possibly of other acylated ligands) is located in a large N-terminal highly hydrophobic pocket of CD14 monomers [14, 15]. The transfer of LPS to CD14 is facilitated by albumin which shields the hydrophobic lipid A when LPS moves across an aqueous milieu [16]. Subsequently, CD14 transfers the LPS to MD-2 in the TLR4/MD-2 complex, again with the assistance of albumin [17-19]. One fatty acid residue of LPS is expected to bind outside the pocket and to facilitate the association of CD14 with MD-2 [15].

Similarly to CD14, a hydrophobic pocket of MD-2 accommodates most of the lipid portion of LPS, however, one of the six acyl chains of the endotoxin is left outside the pocket and interacts with the ectodomain of a neighboring TLR4 molecule. Additionally, the phosphate groups of lipid A interact with positively charged amino acids of TLR4. By simultaneously binding to MD-2 and to the adjacent TLR4 receptor, LPS facilitates formation of "M" shaped dimers of TLR4/MD-2 complexes [8, 20-22]. The TLR4 dimerization facilitates recruitment of two pairs of adaptor proteins, TIRAP/MyD88 and TRAM/TRIF, to the TIR domain of the receptor by homotypic TIR-TIR interactions. MyD88 then recruits the IRAK4 and IRAK2 (or IRAK1) kinases in a hierarchic manner and a so-called myddosome is assembled [23, 24]. This multimolecular complex triggers a signaling cascade leading to early-phase activation of NFKB and MAP kinases and controls the production of pro-inflammatory cytokines like tumor necrosis factor- $\alpha$ (TNF- $\alpha$ ), interleukin-6 (IL-6), etc. On the other hand, TRIF initiates a signaling pathway which activates IRF3 transcription factor, leading to the expression of type I interferons (IFN) and IFN-inducible chemokines like IL-10 and RANTES; late-phase activation of NFKB and MAP kinases follows [25]. Recent discoveries underscore the dichotomy of the MyD88- and TRIFdependent signaling pathways of TLR4 demonstrating that the TRAM/TRIF adaptors are recruited to TLR4 after the receptor is endocytosed [26-28].

Lipopolysaccharide has been shown to induce co-clustering of TLR4 with CD14 and also with heat shock proteins 70 and 90 (Hsp70, Hsp90), CD55, CD11b/CD18, chemokine receptor 4 (CXRC4), Fc $\gamma$ receptors and scavenger receptors (SR) [29-32]. Some of these proteins can function as LPS-binding proteins; however, signaling properties of CXCR4 and class $\mathrm{B}$ scavenger receptors, including CD36, CLA-1/SRB-I, and CLA-2/SRB-II, have been reported [33-35]. A contribution of scavenger receptor $\mathrm{A}$ (SR-A) to maximal NFKB activation and subsequent TNF- $\alpha$ production in LPS-stimulated macrophages has been shown, although the receptor also co-operates with CD14 in the uptake of large amounts of LPS, leading to its detoxification [32, 36]. Recent studies have unveiled an alternative, TLR4-independent, activation of proinflammatory responses to LPS. When high concentrations of LPS persist in the body, LPS can be aberrantly found in the cytoplasm of macrophages where it binds to murine caspase-11 (human caspase-4 and -5) and activates a noncanonical inflammasome leading to the generation of proinflammatory IL-1 $\beta$ and IL-11, and to pyroptosis [37-39].

Due to the complexity of the "LPS-sensing apparatus" in immune cells our understanding of LPS-induced signaling is still incomplete and likely oversimplified. A line of data indicates that an important factor governing TLR4 activation by LPS is the association of TLR4 and its accessory proteins with microdomains of the plasma membrane named rafts. In this review, we summarize the knowledge on the involvement of raft proteins which include CD14 and Lyn kinase in LPS-induced activation of cells. As an increasing body of data suggests that other raft proteins, like CD44 and CD36, co-operate with TLR4 in the induction of the pro-inflammatory responses not only to LPS but also to endogenous ligands, we address these issues following the presentation of LPS-induced responses. Several other aspects of TLR functioning, in particular those of TLR4, have been discussed in previous excellent reviews $[1,3,25,40]$.

\section{Rafts as platforms of TLR4 activation}

Plasma membrane rafts are envisioned as nanoscale assemblies of saturated sphingolipids, cholesterol, and selected proteins which separate laterally for subsecond lifetime in the glycerophospholipid-rich milieu of the membrane [41, 42]. This concept of a dynamic heterogeneous plasma membrane organization has largely been accepted after years of studies and disputes taking place since the principles of raft assembly had been proposed [43]. The assembly of rafts is driven by preferential interactions between cholesterol and long saturated acyl chains of sphingolipids, and also by the capacity of sphingolipids for intermolecular hydrogen bonding. The process is mimicked by liquid ordered $\left(L_{\mathrm{o}}\right)$ and disordered $\left(L_{\mathrm{d}}\right)$ phase separation of lipids in model membranes which 
depends solely on cholesterol-sphingolipid interactions [42, 44-46]. However, the composition of the plasma membrane is far more complicated and multifarious lipidlipid, lipid-protein, and protein-protein interactions affect the formation of nanoscopic raft domains and facilitate their clustering into more stable functional platforms at physiological conditions [47-49]. The inherent propensity of the plasma membrane components to form nanoscopic rafts has been demonstrated in studies using vesicles/ spheres of the plasma membrane obtained by osmotic swelling or chemically induced vesiculation of cells. In these plasma membrane fragments, separation of $L_{\mathrm{o}}$ and $L_{\mathrm{d}}$ phases accompanied by accumulation of selected membrane proteins in the ordered phase can be observed [47, 49-51].

Several mechanisms facilitate the association of proteins with sphingolipid/cholesterol assemblies. Due to the high content of saturated acyl chains of sphingolipids in such assemblies, the thickness of the lipid bilayer and lipid packing increase locally in comparison with the surrounding bilayer composed mainly of unsaturated glycerophospholipids. This, in turn, creates conditions at which insertion of proteins modified with saturated lipids into those domains rather than into the membrane bulk is energetically favorable. For these reasons, in the outer leaflet of rafts, proteins with glycosylphosphatidylinositol (GPI) anchor, like CD14, are accumulated [52]. The inner leaflet of rafts preferentially accommodates proteins modified by palmitoylation, which include tyrosine kinases of the Src family and $\mathrm{G} \alpha$ subunits of trimeric G proteins [53]. Reciprocally, palmitoylated proteins can facilitate the assembly of rafts [54]. There are also some transmembrane proteins, mostly palmitoylated ones, that are intrinsically targeted to rafts, as exemplified by CD44 and CD36 involved in TLR4 signaling (see below) and Cbp/PAG and NTAL multipurpose adaptor proteins [55-59]. In fact, the presence of palmitoylation, the length and the amino acid sequence of the protein transmembrane domain, and the oligomerization status of the protein are now recognized as essential factors controlling the partition of transmembrane proteins to rafts $[60,61]$. It has also been proposed that cholesterol- and sphingolipid-rich shells adjacent to the transmembrane domains of proteins facilitate their association with rafts [62]. In contrast, a transmembrane domain coupled to an unsaturated phosphatidylethanolamine can exclude the protein from rafts [49]. A combination of lipid-lipid and lipid-protein interactions in living cells is likely to give rise to plasma membrane rafts of different protein composition [49].

Raft occurrence is manifested upon cell stimulation, when they merge into larger platforms and facilitate interactions of some receptors with their proximal signaling molecules. This mode of action is common to immunoreceptors, including $\mathrm{T}$ cell receptor (TCR), Fc $\gamma$ receptor IIa (Fc $\gamma$ RIIa), B-cell receptor (BCR), and Fce receptor I (FceRI), which trigger signaling cascades after phosphorylation by raft-anchored tyrosine kinases of the Src family [57, 63-65]. Raft-based platforms also function in cell polarization and membrane trafficking from the Golgi apparatus to the plasma membrane, and during endocytosis (see $[66,67]$ for review). All these events are relevant to LPS-induced activation of macrophages drawing attention to rafts as potential sites of LPS interaction with CD14 and TLR4.

The plasma membrane rafts share lipid composition with caveolae, flask-shaped invaginations of the plasma membrane stabilized by caveolin 1-3 proteins. Contribution of caveolae to macrophage functioning is unclear, although depletion of caveolin-1 inhibited phagocytosis of Escherichia coli, decreased amounts of CD14, CD36, and TLR4, and reduced cytokine production in macrophages and $\mathrm{cavl}^{-/-}$mice exposed to the bacteria [68].

Ample data indicate that TLR4 and accessory proteins can associate with plasma membrane rafts and the TLR4raft association is stimulated by LPS (Table 1). Such results have been obtained in studies based on density gradient centrifugation of Triton X-100 cell lysates yielding detergent-resistant membrane (DRM) fraction [29, 31, 69]. This approach is based on model membrane studies indicating that regions of the plasma membrane rich in saturated lipids and cholesterol are insoluble in non-ionic detergents, like Triton X-100, due to the tight packing of the lipids [70]. DRM fragments can be subsequently separated from other membrane and cytosol components based on their low density due to high lipid content. Ample studies have indicated that the protein and lipid composition of the DRM fraction isolated in density gradients is variable and depends on the protocol used, in particular the detergent type and its concentration, temperature, and duration of cell solubilization [71-73]. One possible reason of this DRM variability is selective extraction of proteins depending on the strength of their association with native rafts in the membrane or, conversely, incorporation of nonraft proteins during membrane solubilization [74, 75]. Thus, although isolation and characterization of the DRM fraction is a useful approach for raft analysis, it should be born in mind that the DRM fraction is not identical with rafts of the intact plasma membrane. It has been hypothesized, however, that the different composition of isolated DRMs can actually reflect the inherent variability of protein concentration affecting lipid order in native plasma membrane rafts [49].

Due to technical limitations of detergent-based biochemical approaches, microscopic techniques are especially useful for examining native rafts in living cells. In recent years, studies on rafts have benefited 


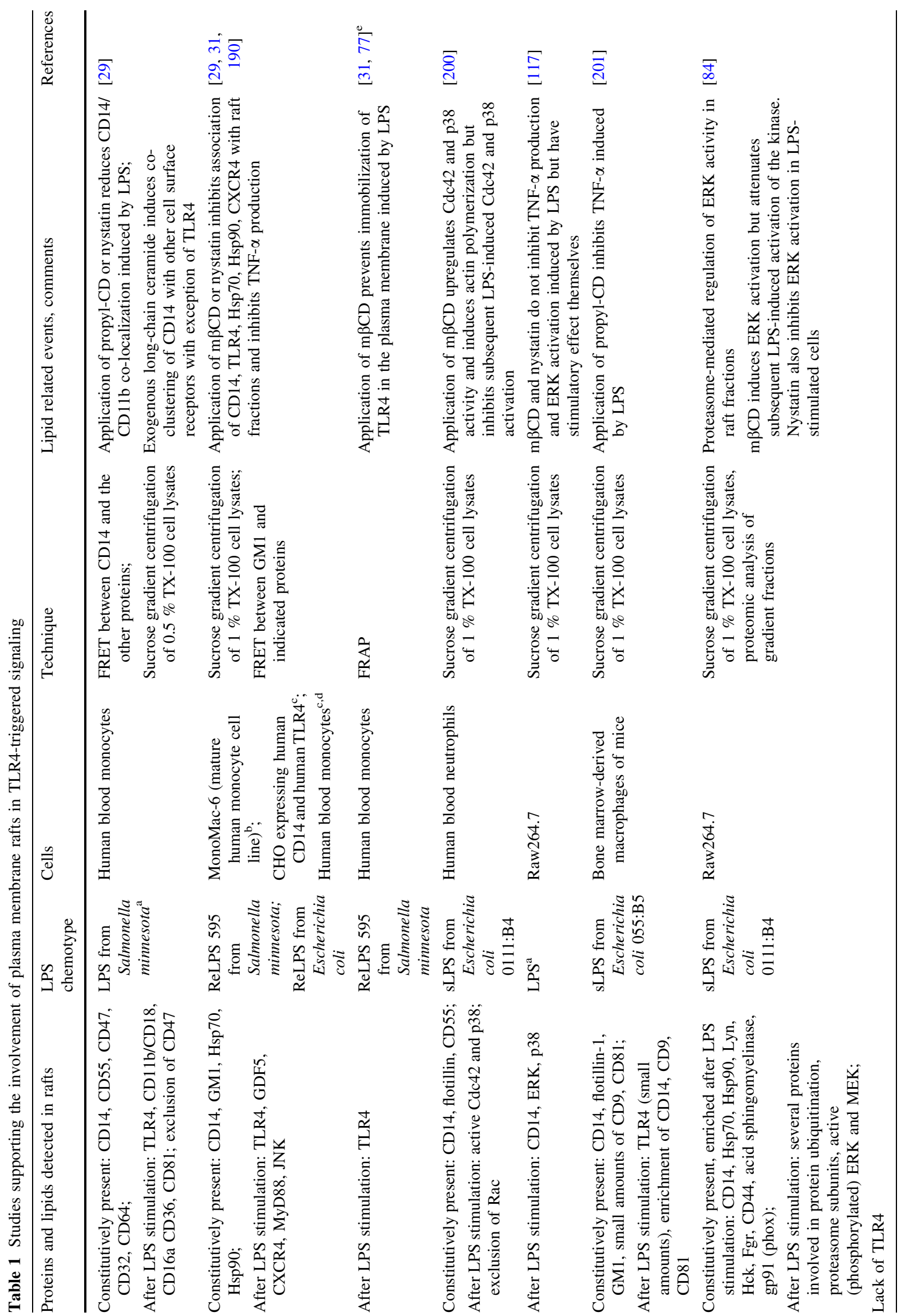




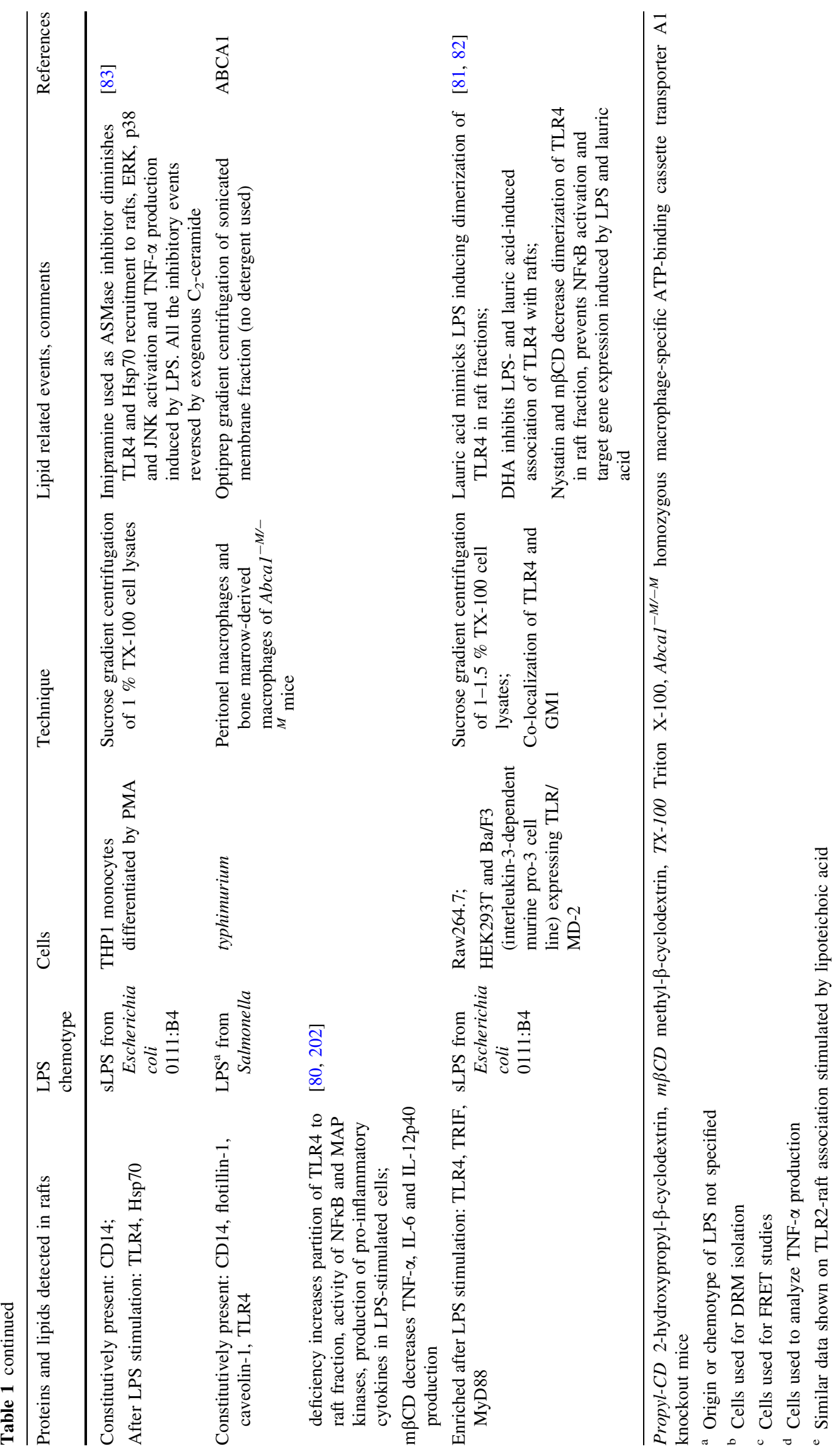


exceptionally from the development of super-resolution microscopy [76] which is yet to be employed to studies on the involvement of plasma membrane rafts in LPS-triggered signaling. Thus far, in support of the biochemical data, measurements of the fluorescence resonance energy transfer (FRET) between the constitutive raft components GM1 or CD14 and selected plasma membrane proteins have indicated that LPS induces the assembly of a raftassociated multimolecular complex composed of TLR4 and other proteins potentially involved in LPS recognition $[29,69]$. In line with these data, LPS has been shown to reduce the lateral mobility of TLR4 in the plane of the plasma membrane. This LPS-induced confined diffusion of TLR4, revealed by measurements of fluorescence recovery after photobleaching (FRAP), has been ascribed to TLR4 trapping within plasma membrane rafts [31, 77].

Taking into account that raft assembly is driven by interactions of sphingolipids and cholesterol, the observed disturbances in TLR4 signaling following changes of the cellular level of these lipids favor the idea of raft involvement in LPS-induced inflammatory responses (Table 1). Extraction or sequestration of cholesterol with cyclodextrin or nystatin has been shown to disturb clustering of TLR4 and accessory proteins in rafts and to inhibit LPS-induced TNF- $\alpha$ production $[29,69,77]$. On the other hand, a deficiency of ATP-binding cassette transporters A1 or G1, linked with cholesterol elevation and an apparent increase of raft content in macrophages, enhanced the partition of TLR4 to raft fractions and augmented proinflammatory signaling [78-80]. Similarly, the proinflammatory effect of an exposure of RAW264 cells to saturated fatty acids $[81,82]$ can be interpreted as a result of enhanced raft assembly.

It is noteworthy that the majority of data supporting LPS-induced accumulation of TLR4 in rafts and the assembly of a raft-based multimolecular complex containing TLR4 were obtained by microscopic and biochemical studies of monocytes and cells of established monocyte lines [29, 31, 69, 83]. In contrast, a recent proteomic analysis of the DRM fraction isolated from RAW264 macrophage-like cells indicated a lack of TLR4 in this raft-derived fraction, regardless of LPS stimulation [84]. Those data suggest that in macrophages the association of TLR4 with rafts can be dynamic and/or too weak to allow its preservation during fractionation of Triton X-100 cell lysates over density gradients. In accordance, studies on the co-localization of TLR4 and CD14 in J774 macrophage-like cells showed that the proteins co-localized transiently and their coincidence was confined to lamellae of LPS-stimulated cells [85]. Despite the failure to detect TLR4 in the DRM fraction of RAW264 cells, the proteomic analysis identified several dozen proteins which were either enriched or recruited to this fraction after 5 and
30 min of LPS stimulation [84]. The list of proteins enriched in the DRM after LPS stimulation includes CD14, CD44, Src family tyrosine kinases Lyn, Hck, and Fgr, Hsp70, Hsp90, acid sphingomyelinase, and NADPH oxidase subunit gp91 ${ }^{\text {phox }}$, supporting other ample data on the involvement of these proteins in TLR4 signaling.

\section{Participation of CD14 in LPS binding and signal transduction}

CD14 is more than LPS-binding protein

The role of CD14 as a key component of LPS-induced inflammatory responses was indicated by studies on transgenic mice expressing human CD14 and mice deficient in CD14. The transgenic mice were hypersensitive to LPS while mice devoid of CD14 did not develop septic shock or accumulate pro-inflammatory cytokines in the blood following exposure to E. coli or intraperitoneal injection of LPS at a dose lethal to wild-type mice [86-88]. This protective effect of CD14 deficiency reflects a fatal role of this protein in exaggerating the inflammatory response in the course of systemic septic shock, although during local infection, the CD14 involvement in combating invading bacteria can be beneficial, as discussed by Zanoni and Granucci [89].

CD14 has long been considered mainly as a molecule which concentrates and delivers LPS to TLR4/MD-2 facilitating TLR4 activation [17, 90]. Originally, however, CD14 was envisioned as a pattern recognition receptor [91], but a lack of a transmembrane and cytoplasmic domain called the signaling role of CD14 into question. The importance of the membrane localization of CD14 for LPS-induced signaling was also negated by the fact that a soluble CD14 (sCD14) devoid of the GPI moiety could substitute for membrane CD14 (mCD14) endowing cells that normally do not express CD14 or express it at a very low level, like endothelial and epithelial cells, as well as $C d 14^{-1-}$ macrophages, with the ability to produce TNF- $\alpha$ and some other pro-inflammatory cytokines in response to LPS stimulation [87, 92, 93].

Indications of a more complex role of CD14 in LPSinduced responses have come from a series of studies performed by the Goyert's and Beutler's groups. The former one found that some genes, like $I P-10$, that are now known to be TRIF-dependent, were minimally expressed in macrophages isolated from $\mathrm{Cd} 14^{-1-}$ mice and stimulated with K235 LPS of E. coli. Simultaneously, expression of genes encoding TNF- $\alpha$ and IL- $1 \beta$ could be induced in a CD14-independent manner [94]. Studies of Beutler and coauthors have unraveled a general picture of a disparate requirement for CD14 to trigger the MyD88-dependent and 
TRIF-dependent signaling pathways of TLR4. In addition, the involvement of CD14 was found to differently determine TLR4 responses to so-called smooth (s) and rough (r) chemotypes of LPS [88]. rLPS is produced by some Gram-negative bacteria, especially Enterobacteriaceae with mutations in genes involved in the O-chain synthesis. Therefore, it is devoid of the $O$-polysaccharide chain and can bear incomplete core oligosaccharides in contrast to the sugar-linked smooth (s) LPS produced, e.g., by most $E$. coli strains including the K235 strain. In studies on sLPS and rLPS signaling requirements, $N$-ethyl- $N$-nitrosourea-mutated mice were used bearing a recessive Heedless mutation identified as a premature stop codon in $C d 14$ gene [88]. The lack of CD14 expression abolished the TRIF-dependent pathway regardless of the LPS chemotype used for cell stimulation. Thus, macrophages isolated from Heedless homozygotes failed to produce type I IFN as a consequence of a lack of IRF3 activation and did not display induction of IFN-inducible genes in response to sLPS or lipid A. Accordingly, no type I IFN was found in the blood of Heedless mutant mice injected with sLPS or rLPS. In summary, both sLPS and rLPS seemed to share a common requirement for $\mathrm{CD} 14$ participation in triggering TRIF-dependent signaling (Fig. 2a-c). This important finding was addressed in further studies on the CD14 signaling abilities discussed below.

There was, however, a clear distinction between the ability of SLPS and rLPS to induce TNF- $\alpha$ production in the absence of CD14. Both mice and ex vivo macrophages bearing the Heedless mutation failed to produce TNF- $\alpha$ in response to sLPS but retained the ability to generate TNF- $\alpha$ as a result of the activation of NFKB and MAP kinases after exposure to rLPS or lipid A. The data suggested that MyD88-dependent signaling can be generated by TLR4/ MD-2 alone in response to rLPS but triggering this signaling pathway by sLPS requires CD14 (Fig. 2b, c). Such a strict requirement of CD14 for sLPS-induced TNF- $\alpha$ production can be typical for lower doses of sLPS, as parallel ex vivo studies performed on $\mathrm{Cd} 14^{-/}$macrophages by the Goyert's group indicated that at concentrations equal or higher than $100 \mathrm{ng} / \mathrm{ml}$ sLPS displayed some potency for TNF- $\alpha$ induction. This potency was higher for rLPS [95]. Although both groups interpreted their data differently, both sets of results in fact seem to indicate that CD14 participation ameliorates the differences between the ability of rLPS and sLPS to activate TLR4. This assumption is supported by recent in vivo studies in which rLPS and sLPS elicited nearly similar accumulation of pro-inflammatory cytokines in the serum of mice injected with $1 \mathrm{mg} /$ $\mathrm{ml}$ of the endotoxin [96]. These data leave unresolved the question of the meaning of the ability of rLPS to activate cells in a CD14-independent manner. It is conceivable that rLPS can induce production of pro-inflammatory cytokines in CD14-negative cells which otherwise can benefit also from the assistance of sCD14, as discussed above. In agreement with this assumption, it was found that mast cells, which do not express CD14, produce IL-6 when stimulated with rLPS but not sLPS [93].

Subsequent studies performed on RAW264 cells exposed to antibodies blocking the LPS binding to CD14 showed that the requirement for CD14 participation in LPS-induced signaling vary depending on the concentration of both sLPS and rLPS. At low doses of LPS $(<10 \mathrm{ng} /$ $\mathrm{ml}), \mathrm{CD} 14$ is crucial for the production of TNF- $\alpha$ and RANTES (used to gauge MyD88- and TRIF-dependent signaling, respectively) induced by either LPS chemotype [97] (Fig. 2d). These data are consistent with earlier findings showing that participation of CD14 markedly increases responsiveness of cells to low concentrations of rLPS or sLPS [90, 95]. At higher doses, sLPS induces moderate production of TNF- $\alpha$ also without the CD14 participation (Fig. 2e), resembling results of earlier studies of the Goyert's group [94, 95]. Notably, rLPS in these conditions activates the moderate production of both TNF$\alpha$ and RANTES (Fig. 2f). In addition, an assistance of LBP was indispensable to induce maximal generation of these cytokines in response to sLPS but not to higher doses of rLPS [97, 98]. In summary, it is clear that rLPS relies on CD14 assistance to a lower extent than does sLPS in activating TLR4, and of the two signaling pathways triggered by TLR4, the involvement of CD14 is especially important for the TRIF-dependent one.

Questions arise as to the molecular mechanism of CD14 (and LBP)-independent activation of cells by LPS. In the absence of CD14, albumin can bind LPS monomers without the assistance of LBP and deliver them to TLR4/MD-2 [99]. Alternatively, LPS could be incorporated into rafts of the plasma membrane and subsequently bind to the receptor complex. The membrane incorporation could be facilitated by the lack of the O-chain and thus higher hydrophobicity of rLPS in comparison with sLPS [93]. Integration of LPS into the plasma membrane could also be potentiated by the aggregated state of rLPS [100]. The incorporation of rLPS into membranes can induce profound changes of the membrane raft organization, as revealed by studies on the interaction of ReLPS (the shortest form of rLPS also used in $[88,97]$ ) with model membranes performed by solid-state NMR spectroscopy. When mixed with DEPE/sphingomyelin/cholesterol liposomes, a ternary lipid mixture in which the sphingomyelin/cholesterol-rich $L_{\mathrm{o}}$ phase co-exists with the DEPE-rich $L_{\mathrm{d}}$ phase, ReLPS induced coalescence and expansion of the $L_{\mathrm{o}}$ phase [101]. These data correspond with the results of microscopic studies on LPS organization in giant liposomes composed of polar lipids isolated from E. coli. In these membranes, rLPS formed micron-sized gel-like microdomains while 

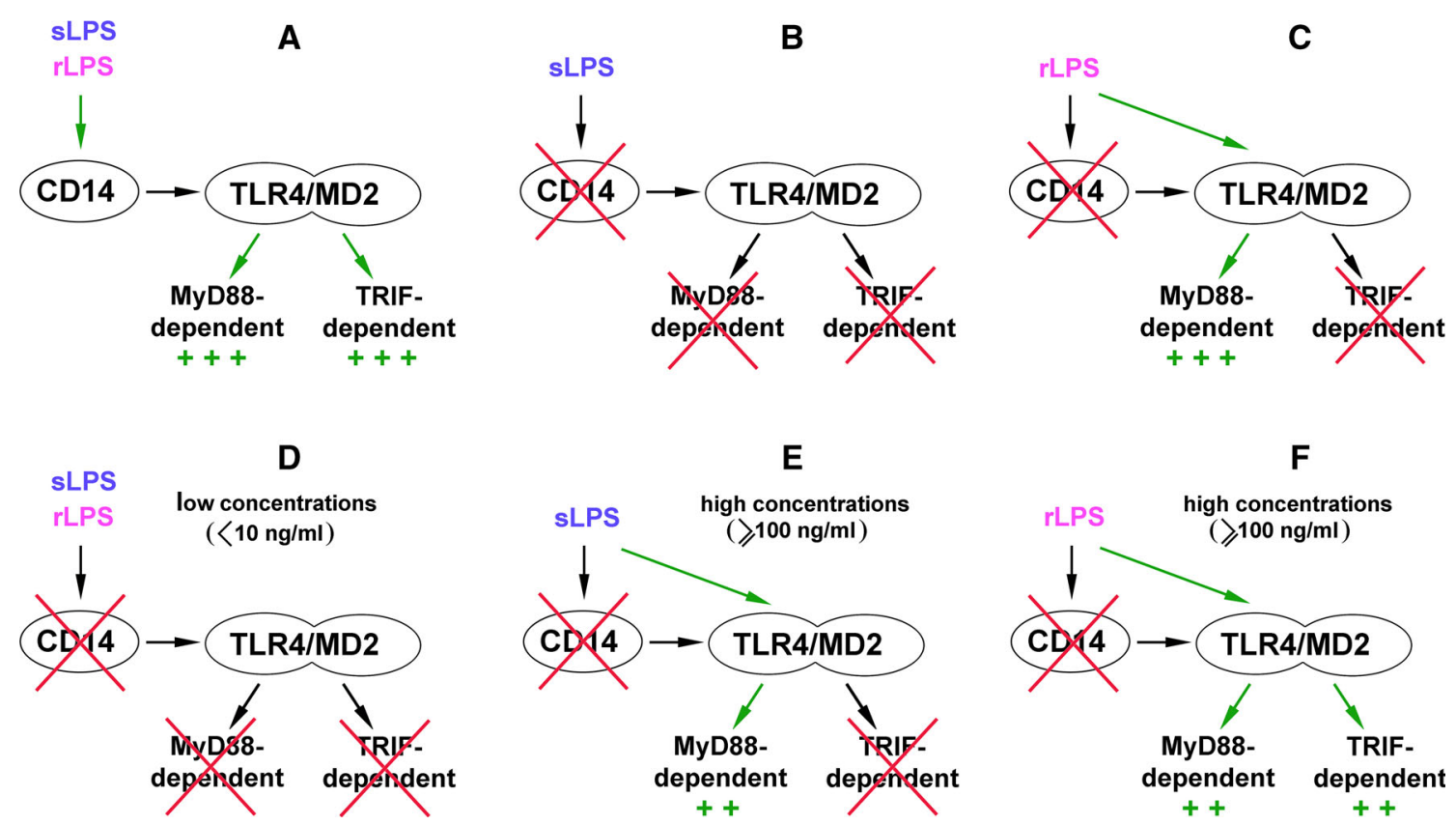

Fig. 2 Participation of CD14 in TLR4 signaling pathways triggered by sLPS and rLPS. a In the presence of CD14, sLPS and rLPS activate TLR4 and trigger MyD88- and TRIF-dependent pathways with similar intensity. b, c Studies performed on macrophages bearing the Heedless mutation of $C d 14$ have indicated that sLPS requires CD14 to activate TLR4 (b), while rLPS can induce TRIF-dependent signaling of TLR4 in CD14-deficient cells (c). d-f Other studies suggest that the requirement of CD14 for activation of TLR4 varies

sLPS formed small clusters about $380 \mathrm{~nm}$ in diameter [102]. A line of other studies performed on model membrane also indicated that sLPS can spontaneously incorporate into membranes. The preferred sites of sLPS binding and incorporation were sphingomyelin/cholesterolrich domains formed in DOPC/sphingomyelin/cholesterol liposomes [103, 104]. These findings suggest the importance of a direct interaction of rLPS and sLPS with plasma membrane rafts. In the case of rLPS, its incorporation could efficiently induce coalescence of rafts, possibly inducing TLR4 dimerization and pro-inflammatory signaling. The coalescence of nanoscale rafts into more stable, larger raft domains is fundamental for their functioning in the plasma membrane. It causes co-patching of raft proteins and lipids into functional signaling platforms with simultaneous exclusion of non-raft proteins [42].

It should be noted that in model membrane studies discussed above relatively high LPS concentrations (e.g., in the range of $\mu \mathrm{g} / \mathrm{ml}$ [103]) were used to reveal changes of membrane organization. Stimulation of cells with high doses of LPS could also facilitate a direct action of LPS, particularly rLPS, on the plasma membrane. This assumption could explain the activation of TRIF signaling by $100-1,000 \mathrm{ng} / \mathrm{ml} \mathrm{rLPS}$ in RAW264 cells even when the binding of rLPS to CD14 was inhibited, and the lack of depending on the concentration of the endotoxin. At low concentrations, sLPS or rLPS are unable to activate TLR4 without the involvement of CD14 (d). At higher doses of sLPS, CD14 is dispensable for initiation of MyD88-dependent pathway of TLR4, although the production of TNF- $\alpha$ is submaximal in these conditions (e). When present in relatively high concentrations, rLPS can induce submaximal activation of both signaling pathways of TLR4 without binding to $\mathrm{CD} 14$ (f)

such activation by $10-100 \mathrm{ng} / \mathrm{ml} \mathrm{rLPS}$ or lipid A in CD14deficient macrophages bearing the Heedless mutation [88, 97] (Fig. 2c vs. f). These data suggest that, when present in higher concentrations, rLPS can trigger TRIF-dependent signaling bypassing the requirement for the binding to CD14 which is otherwise required for the internalization of TLR4/LPS leading to TRIF recruitment, as discussed in the next section.

\section{CD14 participates in internalization of TLR4/LPS}

Both sLPS and, to a lower extent, rLPS rely on CD14 assistance to activate the TRIF-dependent pathway of TLR4 (Fig. 2). Why is the CD14 participation required for activation of this pathway?

The importance of CD14 for the initiation of the TRIFdependent pathway has been linked with internalization of TLR4 which is essential for this signaling cascade. The link between the endocytosis of LPS-activated TLR4 and the subsequent TRIF-mediated signaling has been shown by a line of data. It has been demonstrated that the surface level of the receptor decreases in LPS-stimulated macrophages, monocytes, and CD14/TLR4/MD-2-transfected $\mathrm{Ba} / \mathrm{F} 3$ cells. TLR4 co-localized with markers of early/ sorting endosomes and its clearance from the cell surface 
was inhibited by dynasore, an inhibitor of the GTPase dynamin controlling the pinching-off of endocytic vesicles [26, 27, 105]. Concomitantly, dynasore abolished the TRIF-dependent signaling indicating that endocytosis of TLR4/LPS is important for this signaling pathway of TLR4 $[27,36]$. The endocytosis of TLR4 is supposed to follow MyD88-dependent signaling originating from the plasma membrane $[27,105,106]$ and the switch from the plasma membrane MyD88-based to the TRIF-dependent endosomal signaling of TLR4 could be controlled by phosphatidylinositol 4,5-bisphosphate $\left[\mathrm{PI}(4,5) \mathrm{P}_{2}\right]$ turnover in the plasma membrane. The drop of $\mathrm{PI}(4,5) \mathrm{P}_{2}$ level in the membrane of endosomes was proposed to facilitate the disassembly of the TIRAP/MyD88 signaling complex and association of TRAM/TRIF adaptors [27, 107]. In support of this thesis, the MyD88-dependent activation of NFKB was enhanced in HEK293-CD14/TLR4/MD-2 transfectants when the endocytosis of TLR4 was disrupted [26]. Overaccumulation of $\mathrm{PI}(4,5) \mathrm{P}_{2}$ in dendritic cells as a result of inactivation of the $110 \delta$ isoform of class I phosphatidylinositol 3-kinase (PI3-kinase), which phosphorylates $\mathrm{PI}(4,5) \mathrm{P}_{2}$ to phosphatidylinositol 3,4,5-trisphosphate $\left[\mathrm{PI}(3,4,5) \mathrm{P}_{3}\right]$, was one of the means of achieving this goal [106].

A line of data indicates that CD14 controls the internalization of LPS-activated TLR4. Indeed, studies performed on bone marrow-derived macrophages and dendritic cells confirmed a significant time-dependent decrease of the cell surface level of TLR4 in wild type but not in $\mathrm{Cd}_{14^{-1-}}$ cells exposed to $1 \mu \mathrm{g} / \mathrm{ml}$ sLPS [28]. Simultaneously, the CD14-deficient cells failed to trigger TRIF-dependent signaling in response to sLPS, in agreement with results of earlier studies discussed above [88, 94, 97]. It has been established that the clearance of CD14 and TLR4 from the cell surface, and subsequent IRF3 activation, and type I IFN production all require the activity of Syk kinase. Syk binds to proteins containing the immunoreceptor tyrosine-based activation motif (ITAM) and contributes to the downstream activation of phospholipase $\mathrm{C} \gamma 2$ (PLC $\gamma 2$ ) [28]. Furthermore, PLC $\gamma 2$, but not PLC $\gamma 1$, was found to account for inositol trisphosphate $\left(\mathrm{IP}_{3}\right)$ generation and subsequent release of $\mathrm{Ca}^{2+}$ from intracellular stores required for TLR4 endocytosis and IRF3 activation in RAW264 cells and bone marrow-derived murine macrophages [108]. These data support the idea that CD14 controls TLR4/LPS macropinocytosis by activating ITAM-mediated events which lead to Syk-PLC $\gamma 2$-dependent internalization of TLR4 [28] (Fig. 3a). This proposed chain of events is independent of the Src kinase-PLC $\gamma 2$ axis found to control NFAT activation in dendritic cells only $[109,110]$. The data on TLR4 endocytosis confirmed a biphasic scenario of TLR4 activation with the second phase being dependent on the
CD14-controlled internalization of the LPS/CD14/TLR4 complex. It is noteworthy that macropinocytosis of LPS/ CD14/TLR4 can overlap the CD14- and SR-A-mediated uptake of LPS leading to is detoxification. This non-signaling uptake of LPS does not involve TLR4 and in fact can compete with the TLR4/LPS uptake which contributes to TLR4 signaling [36, 111].

The endosomal origin of the TRIF-dependent signaling of TLR4 has been verified by the effects exerted on the signaling by phagocytosis of $E$. coli by macrophages and dendritic cells. The phagocytosis was expected to bypass the lack of CD14 in knockout cells, force TLR4 internalization and eventually induce generation of the TRIFdependent cascade. The prediction turned out to be correct for dendritic cells only. In CD14-deficient macrophages, the phagocytosis of $E$. coli failed to restore endocytosis of TLR4 and TRIF signaling [28]. The authors ascribed those contrasting results to a more "permissive" nature of dendritic cells facilitating TLR4 uptake in the absence of CD14 (Fig. 3b).

Some studies questioned the need of TLR4 internalization for triggering the TRIF-dependent pathway during phagocytosis of E. coli and instead ascribed the signaling abilities to an intracellular pool of TLR4. This pool of TLR4 resides in Rab11-positive recycling endosomes and can be transported to the E. coli-containing phagosomes, thereby triggering the TRIF-dependent pathway. The authors suggested that the internal pool of TLR4 can induce the TRIF-dependent cascade without previously being engaged in MyD88-dependent signaling in the plasma membrane, provided LPS reaches the endosomal compartment [112]. These data do not explain why the phagocytosis of E. coli by $C d 14^{-1-}$ macrophages, which proceeded without concomitant TLR4 uptake, did not restore TRIF-dependent signaling [28] thereby suggesting that TLR4 delivered to phagosomes from Rab11-bearing endosomes can only amplify TRIF-dependent signaling triggered by internalized TLR4.

Beside phagocytosis of $E$. coli in dendritic cells, one more CD14-independent pathway of TLR4/LPS uptake leading to TRIF activation can be considered. It has recently been found that endocytosis of LPS-containing liposomes can proceed unassisted by CD14 in clathrincoated vesicles (Fig. 3c). Endocytosis of LPS liposomes led to IRF3 activation and RANTES production in macrophages without a concomitant TNF- $\alpha$ and IL-6 release [113]. Such endocytic pathway could also explain the CD14-independent activation of RANTES production induced at higher doses of rLPS (see Fig. 2f). An involvement of clathrin-coated endocytosis in the internalization of LPS and TLR4/LPS was indicated by electron microscopy and immunofluorescence studies [26, 114]. About ten times more LPS is internalized in non-coated 


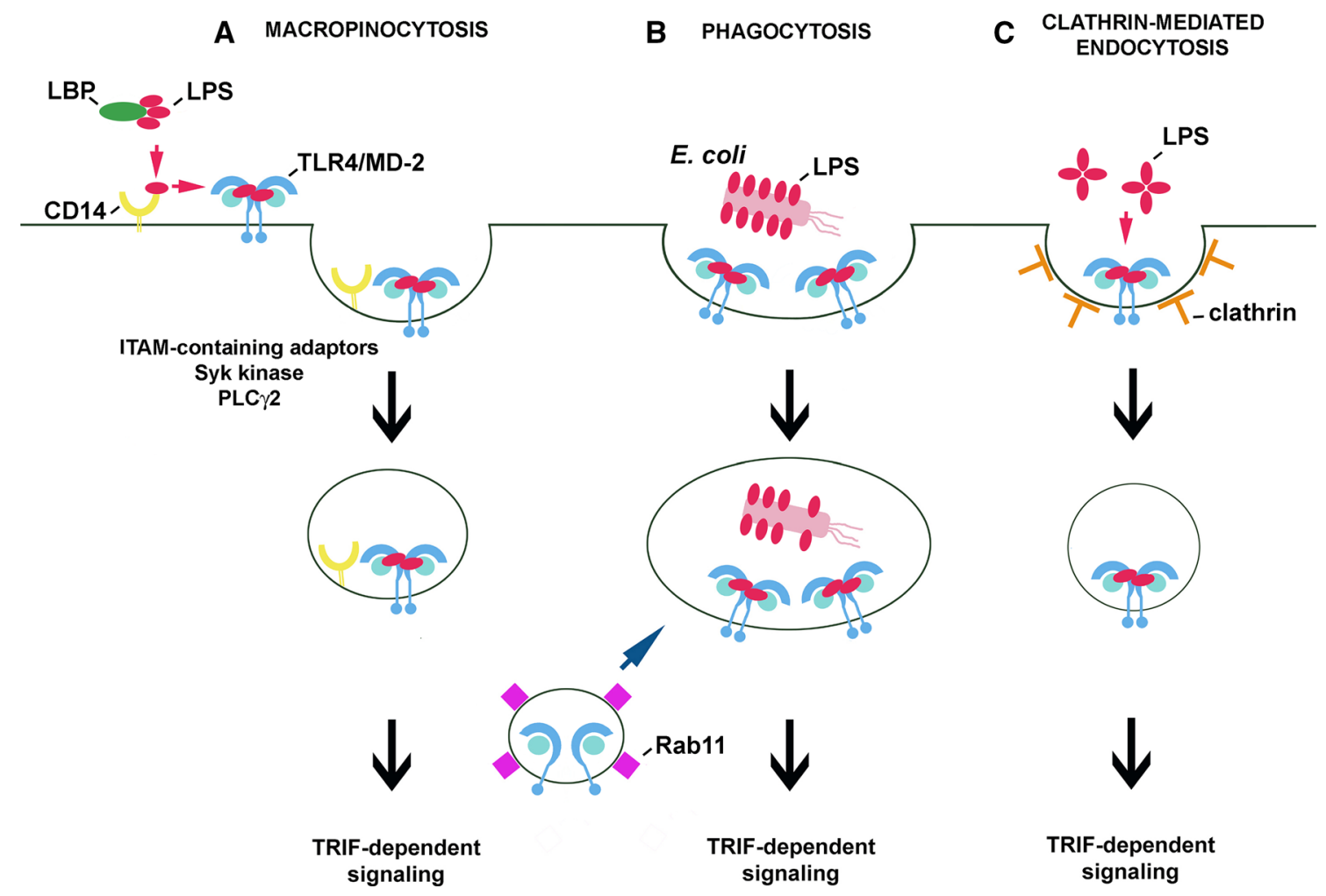

Fig. 3 Routes of internalization of LPS-activated TLR4/MD-2. Internalization of TLR4/MD-2 can be induced in a CD14-dependent (a) or CD14-independent manner (b, c). a When LPS monomers are bound by CD14, the protein transfers the LPS to the TLR4/MD-2 complex which, after inducing the MyD88-dependent pathway (not shown), undergoes macropinocytosis controlled by CD14 and required for TRIF-dependent signaling. Similar steps of TLR4 activation take place during phagocytosis of E. coli in CD14-

than in coated vesicles [114], yet drugs inferring with clathrin-dependent endocytosis significantly inhibit TRIFdependent signaling in LPS-stimulated cells [36, 115]. Further studies are required to reveal whether CD14 affects clathrin-mediated uptake of TLR4/LPS, which factors direct TLR4/LPS for macropinocytosis or clathrin-mediated endocytosis, and whether the pathway of TLR4 internalization modulates its signaling, as suggested for receptor tyrosine kinases [116].

Is raft localization of CD14 crucial for its involvement in LPS-triggered events?

The relevance of the raft association of CD14 to its involvement in TLR4 signaling in monocytes/macrophages, key players in inflammatory reaction, has long puzzled researchers. Circumstantial evidence supporting such dependence came from cell fractionation studies showing enrichment of CD14 in the raft-originating DRM fraction of LPS-stimulated RAW264 cells [84, 117]. A more direct approach to this issue relied on a comparison of expressing cells. b In dendritic cells, phagocytosis of E. coli can bypass the requirement for the involvement of CD14 in TLR4/MD-2 uptake and activation. The intracellular pool of TLR4/MD-2 located in Rab11-containing recycling endosomes can be delivered to phagosomes containing $E$. coli and possibly to endosomes during macropinocytosis. c TLR4/MD-2/LPS complexes can also undergo clathrin-mediated endocytosis, although the initial steps of this process are unclear

cell activation by LPS mediated by GPI-anchored and chimeric transmembrane forms of CD14. For this purpose, CD14 was fused to the transmembrane plus cytoplasmic fragment of either LDL receptor or tissue factor and expressed in THP- 1 cells $[114,118,119]$. The CD14-tissue factor chimera localized to the Triton X-100-soluble fraction, yet it induced NFKB activation, p38 phosphorylation and IL-8 and TNF- $\alpha$ production in a similar manner as its wild-type raft-anchored counterpart [118]. Of note, the MyD88- and TRIF-dependent signaling could not be distinguished at the time when those studies were carried out. It seems, therefore, that the apparent dispensability of GPI anchoring for CD14 functioning can be revisited in view of our present understanding of the distinct requirements for the involvement of CD14 in the two signaling pathways of TLR4.

Raft localization of CD14 can be critical for macropinocytosis of LPS-activated TLR4. The CD14-mediated macropinocytosis of the LPS/CD14/TLR4 complex relies on the formation of large non-coated vesicles and involves Syk kinase activity, as described above [28]. A recent 
discovery of Syk-mediated internalization of CD36, a scavenger receptor localized in rafts (and caveolae), has paved the way for consideration of how CD14 could trigger the LPS/CD14/TLR4 internalization in macrophages. Similarly to CD36, CD14 could facilitate the assembly of a multimolecular complex composed of tetraspanins, $\beta 1$ and $\beta 2$ integrins, and ITAM-bearing Fc $\gamma$ receptors [120]. Notably, FRET analysis indicated that tetraspanin CD81, integrin $\beta 2$ (CD11/CD18) and $\mathrm{Fc} \gamma$ receptors gather in the vicinity of CD14 and TLR4 in LPS-stimulated human monocytes [29, 31, 121] (Table 1). Subsequent binding of Syk to ITAMs, both likely to be phosphorylated by Src family kinases, would then trigger a cascade of phosphorylations of a variety of adaptor and scaffolding proteins, and recruitment of lipid kinases and PLC $\gamma 2$ leading to the activation of Rho GTPases and WASP/Scar proteins. This chain of events could control local actin polymerization providing the driving force for internalization of LPS/CD14/TLR4, as has been deciphered for Fc $\gamma$ receptor-mediated phagocytosis. Taking into consideration that $\mathrm{Fc} \gamma$ receptors are functionally connected with TLR4 and associate with rafts in LPSstimulated cells [29, 121, 122] and that phosphorylation of their ITAMs by Src family kinases in the rafts is well established [64, 65], the CD14-bearing rafts would be preferred sites of the assembly of the multimolecular complex mediating the internalization of LPS/CD14/ TLR4. Induction of raft reorganization by high doses of rLPS, as found in model membrane studies [101], could trigger a similar chain of events leading to TLR4 internalization without prior binding of rLPS to CD14 (see Fig. 2f). A potential caveat of this model that needs to be addressed is the postulated lack of an involvement of Src family kinases in TLR4 internalization inferred from the application of Src inhibitor-1 [28].

In addition to the CD14-controlled macropinocytosis of LPS-activated TLR4, another role is ascribed to CD14 exclusively in dendritic cells. The CD14-dependent NFAT activation in these cells provides a most clear indication that the raft localization of CD14 is critical for its functioning in LPS-stimulated cells. Upon LPS stimulation of dendritic cells CD14 triggers an influx of $\mathrm{Ca}^{2+}$ leading to calcineurin-mediated activation of NFAT independently of TLR4. Eventually, production of IL-2, prostaglandin $\mathrm{E}_{2}$ as well as apoptosis of the cells occurs [109, 110]. To fulfill this function, CD14 needs to be membrane anchored as sCD14 does not support NFAT activation. It was found that mCD14 activates Src kinases and PLC $\gamma 2$ leading to $\mathrm{IP}_{3}$ generation and an influx of extracellular $\mathrm{Ca}^{2+}$ to the cytoplasm. Cholesterol depletion abolished this $\mathrm{Ca}^{2+}$ signaling, suggesting that raft integrity is crucial for the co-operation of CD14 with raft-anchored Src kinases [109].

\section{Involvement of Lyn in LPS-induced TLR4 signaling pathways}

Tyrosine kinases of the Src family in LPS-induced signaling

Toll-like receptor 4 signaling relies on cascades of protein serine-threonine phosphorylation and polyubiquitination events. Activation of this receptor also triggers protein tyrosine phosphorylation catalyzed by multiple protein tyrosine kinases including Bruton's tyrosine kinase [123, 124], Syk kinase [28, 125], and kinases of the Src family [126-128]. Of note, the activity of all these kinases is crucial for the signaling by raft-associated receptors. The most thoroughly characterized examples of that come from studies on the involvement of Src family kinases and Syk kinase in the signaling cascades of receptors containing ITAM signaling motifs, e.g., Fc $\gamma$ RIIa, FceRI, and TCR [64, $65,129]$.

In terms of TLR4 activation, pretreatment of human monocytes and macrophages with herbimycin A or genistein, broad-spectrum inhibitors of tyrosine kinases, or with PP1, an inhibitor of Src family kinases, reduced LPSinduced production of several cytokines like TNF- $\alpha$, IL- $1 \alpha$, IL-6, IL-10, and IP-10, and prevented the activation of MAP kinases and NFKB [126, 127, 130, 131]. In contrast, macrophages isolated form $\mathrm{hck}^{-/-} \mathrm{fgr}^{-1-} \mathrm{lyn}^{-/-}$triple knockout mice released normal or even increased amounts of TNF- $\alpha$, IL-1, IL-6, and NO and showed no impairment of the activation of MAP kinases and NFKB [132]. Doubledeficient $h \mathrm{ck}^{-/} \mathrm{fgr}^{-/-}$mice displayed an increased resistance to endotoxic shock which was ascribed, however, to defective integrin signaling and consequent reduced neutrophil migration into the tissue rather than to a direct effect of the lack of Hck and Fgr activities on cytokine production [133]. The discrepancies between the effects of drug application and the knockout of the tyrosine kinase genes on the pro-inflammatory reaction of cells are likely to be due to the fact that the Src family of protein tyrosine kinases comprises nine members: Src, Lyn, Hck, Fgr, Fyn, Yes, Lck, Ylk, and Blk, of which the first six are known to be expressed in macrophages [131]. All these kinases share a common domain structure, with the $\mathrm{N}$-terminal domain undergoing myristoylation and palmitoylation, the latter facilitating anchoring of the kinase in plasma membrane rafts. The kinases also contain the $\mathrm{SH} 3$ and $\mathrm{SH} 2$ domains, the catalytic domain, and a short $\mathrm{C}$-terminal tail controlling their conformation and enzymatic activity [134]. It has been suggested that the apparent failure to detect changes of LPS-induced responses in the knockout mice resulted from a compensation of the absence of some of the Src kinases by other family members. Indeed, short-term adenoviral overexpresion and siRNA knockdown studies 
have indicated that the Hck kinase activity controls the production of TNF- $\alpha$ and IL- 6 induced by LPS in human macrophages. The kinase affects the activity of AP-1 transcription factor without influencing the activity of MAP kinases or NFKB [128]. LPS also triggers association of Hck with Vav, a Rho family guanine nucleotide exchange factor (RhoGEF) [135] involved in TNF- $\alpha$ production, as discussed below. In addition, Src kinase has been reported to act as a downstream effector of LPSinduced actin cytoskeleton rearrangements [136]. The participation of Lyn kinase in LPS-triggered TLR4 signaling is supported by the most extensive line of data.

\section{A positive role of Lyn in TLR4 signaling pathways}

First indications on the involvement of Lyn kinase in LPSinduced signaling came from studies on CD14 protein. CD14 immunoprecipitated from human monocytes was found to be associated with Lyn kinase. The activity of the kinase increased shortly (1-5 min) after stimulation of the cells with $1 \mathrm{ng} / \mathrm{ml}$ sLPS [126]. Other studies on human monocytes revealed that within 1-5 min of stimulation with $10 \mathrm{ng} / \mathrm{ml}$ of ReLPS, TLR4 underwent tyrosine-phosphorylation [137]. Rapid Lyn activation was also observed in LPS- or taxol-treated mouse peritoneal macrophages [138] and more recently in human macrophages [128]. When expressed in HEK293 cells together with human TLR4 and MD-2, Lyn kinase co-immunoprecipitated with the receptor even in the absence of CD14. Recruitment of Lyn to TLR4 was triggered within 1 min of LPS stimulation of the cells with a maximal response at $15 \mathrm{~min}$. Within the same time frame tyrosine phosphorylation of TLR4 was observed in the TLR4/MD-2-expressing HEK293 regardless of CD14 presence [127]. Those data suggested, although not proved, that Lyn kinase could be responsible for the phosphorylation of tyrosine reside(s) of TLR4. Crucially, further studies using HEK293 cells transfected with a constitutively active human CD4-TLR4 chimera indicated that TLR4 tyrosine phosphorylation was required for TLR4-induced signaling. Thus, mutation of tyrosine residues Y674A and Y680A in the TIR domain of TLR4 inhibited the recruitment of MyD88 and activation of IRAK-1 by the constitutively active form of the receptor. Furthermore, activation of NFkB, phosphorylation of p38 and JNK kinases, and RANTES production were also strongly suppressed, indicating that tyrosine phosphorylation of TLR4 is prerequisite for both the MyD88- and TRIF-dependent pathways. Similar suppression of TLR4 phosphorylation and signaling was found for $\mathrm{P} 714 \mathrm{H}$ human and $\mathrm{P} 712 \mathrm{H}$ murine TLR4, known as mutant receptors unresponsive to LPS [127]. Taken together, the data indicated the importance of protein tyrosine phosphorylation for TLR4 signaling and suggested a positive role of Lyn activity in this process (Fig. 4). The CD14/Lyn association and activation of CD14-associated kinase by LPS, found by Stefanova et al. [126], pointed to the importance of raft localization of Lyn in LPS-triggered signaling of TLR4. To our knowledge, however, this subject has not been addressed directly in any further studies.

In accordance with its plasma membrane localization, Lyn kinase was recently found to bind TRAF6 in response to LPS. TRAF6 is an E3 ubiquitin ligase which transiently associates with the myddosome and controls downstream steps of TLR4 signaling cascades affecting the TAK-1 kinase activity after catalyzing its own polyubiquitination via Lys ${ }^{63}$-linked chains [139]. The involvement of Lyn in LPS-induced TRAF6 activity has been verified with the use of mast cells from $\mathrm{lyn}^{-1-}$ mice [140]. Remarkably, a lowlevel binding of TAK-1 to TRAF6, ubiquitination of TRAF6, and TAK-1 phosphorylation occurred in the $l y n^{-1-}$ mast cells, which were not found in wild-type cells. However, stimulation of the Lyn-deficient mast cells with LPS did not increase the association of TRAF6 with TAK1 , and subsequent ubiquitination of TRAF6 and phosphorylation of TAK-1 were also inhibited. As a result of the impairment of the TAK-1 activation also phosphorylation of ERK1/2, p38 and JNK kinases and NFKB activation were inhibited in the Lyn-deficient mast cells [140]. This scenario resembled the impaired signaling of non-phosphorylated mutants of TLR4 which correlated with their low basal association with MyD88 that was not changed upon LPS treatment in contrast to the LPSinduced MyD88 recruitment by wild-type TLR4 [127]. It seems, therefore, that Lyn can modulate the TLR4/MyD88 and TRAF6/TAK-1 association/disassociation cycles required for optimal TLR4 signaling.

Lyn kinase has been found to associate with TRAF6 in LPS-stimulated mast cells [140]; however, the mechanism of this interaction has not been resolved. An indication on how the TRAF6 and Lyn kinase interaction could be regulated came from studies on TRAF6 functioning in LPSstimulated human lung microvascular endothelial cells. In these cells, LPS binding to TLR4 triggers a cascade of tyrosine phosphorylations catalyzed by kinases of the Src family contributing to the disruption of the endothelial barrier integrity. In the endothelial cells, LPS stimulates the association of TRAF6 with Src and Fyn, but not with Lyn kinase [141], suggesting that identity of the Src family kinase engaged in TLR4 signaling can be cell typedependent. The binding site for the Src kinases has been mapped to a proline-rich region of TRAF6. The assembly of the TRAF6-Src(Fyn) kinase complex requires the kinase enzymatic activity, while silencing of the TRAF6 gene precludes activation of the Src kinases, which does not allow distinguishing which enzyme acts upstream of which [142]. In addition, during the association of TRAF6 with 
Fig. 4 Participation of Lyn in TLR4 signaling. Lyn kinase either associates constitutively with proteins or associates with, and phosphorylates, indicated proteins after stimulation of cell with LPS. These events regulate positively or negatively TLR4induced signaling (left and right side of the figure, respectively). Arrows indicate domains of Lyn most likely involved in binding of indicated proteins. The molecules are drawn not to scale

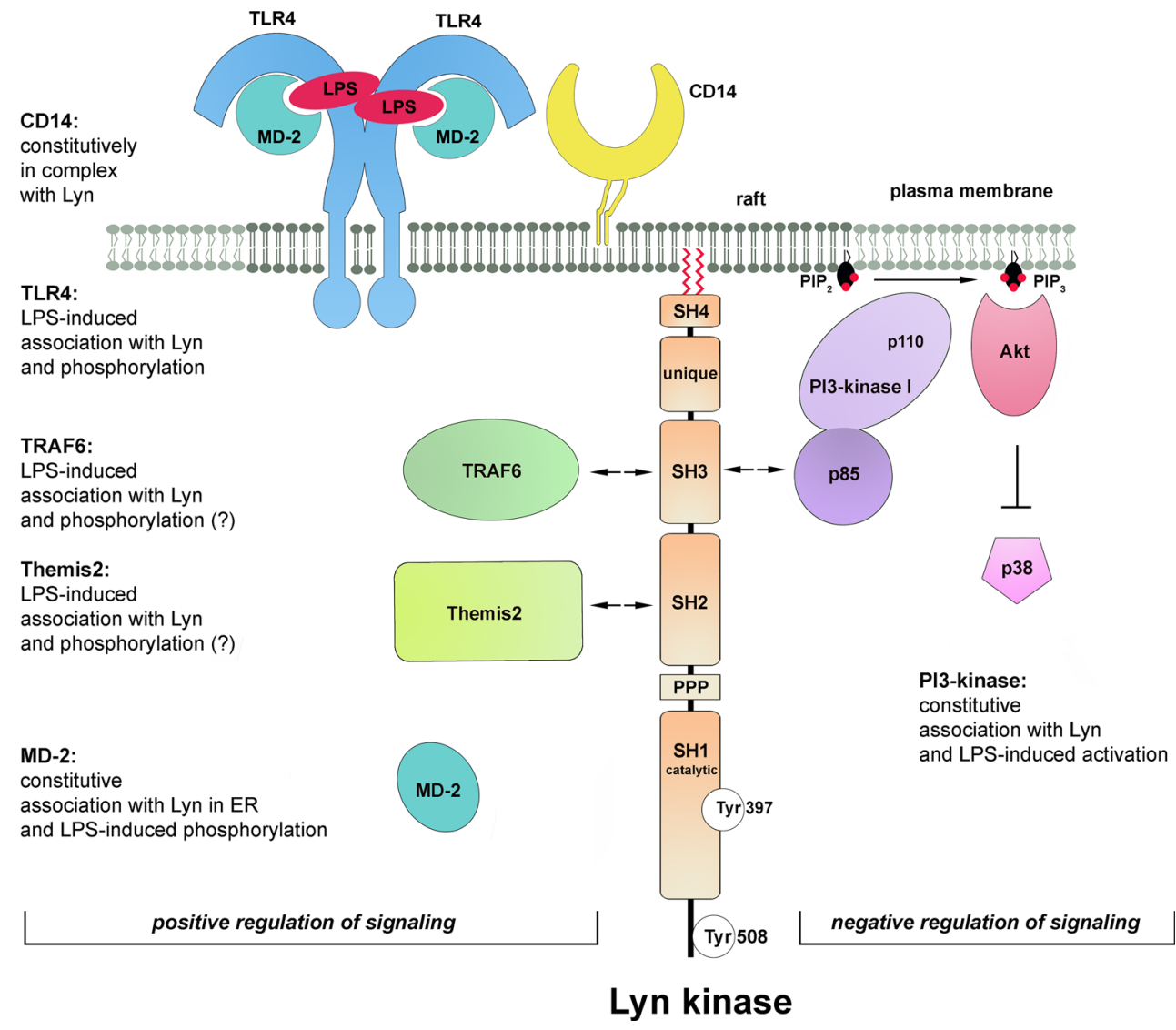

Src(Fyn), each protein can serve as a substrate for the catalytic activity of the other and their ubiquitination/ phosphorylation is catalyzed [142]. If a similar relation holds for the TRAF6-Lyn interaction, Lyn would phosphorylate TRAF6 and stimulate the downstream TRAF6 signaling in LPS-treated cells while TRAF6 would catalyze Lys $^{63}$-mediated ubiquitination of Lyn. Whether this polyubiquitination of Src family kinases affects their activity or association with TRAF6 remains unknown. It has been established that Lys $^{48}$-linked ubiquitination and subsequent proteasomal degradation of Lyn controls its level in cells [143].

Recently, a newly discovered macrophage scaffolding protein Themis2 was found to bind Lyn kinase in LPSstimulated RAW264 cells [144]. Analysis of the Themis2 role has provided evidence for the action of fine-tuning mechanisms of LPS-induced signaling. It was found that Themis2 underwent tyrosine phosphorylation on $\mathrm{Tyr}^{660}$ in LPS-stimulated cells and when phosphorylated could bind $\mathrm{SH} 2$ domain of Lyn kinase, however, the possibility of phosphorylation of Themis 2 by Lyn has not been addressed. On the other hand, a proline-rich sequence of Themis2 binds constitutively the RhoGEF Vav. Therefore, clustering of Lyn and Vav at Themis2 could facilitate Vav phosphorylation by Lyn leading to stimulation of its GEF activity. The Themis2-Lyn-Vav axis has been found to stimulate selectively ERK and p38 activity but not that of JNK, NFKB, or IRF3. Eventually, the signaling events involving Themis 2 and Lyn upregulate the production of TNF- $\alpha$ but not IL-6 or Cox2 in LPS-stimulated cells [144].

Some data indicate that not only plasma membraneassociated Lyn but also its intracellular fraction could be engaged in the signaling in LPS-stimulated cells. Lyn kinase was found to associate constitutively with MD-2 and to mediate its LPS-induced phosphorylation in the endoplasmic reticulum/endosomes of HEK293 expressing TLR4/MD-2 which suggested the MD-2 phosphorylation could be triggered after LPS internalization [145]. A key unresolved question regarding the proposed MD-2 phosphorylation by Lyn is how MD-2, apparently enclosed in the vesicle lumen, could be accessed by the kinase.

To summarize, stimulation of cells by LPS induces rapid activation of Lyn which can be involved in the initial steps of LPS-induced signaling by phosphorylating TLR4. The link between the Lyn and CD14 involvement in LPSinduced signaling, suggested by studies of Stefanova et al. [126] deserves further attention in view of the signaling properties of CD14 discussed in the previous chapter. Lyn kinase also associates with (and phosphorylates ?) TRAF6 and Themis2, downstream TLR4 signaling proteins, and 
can phosphorylate endosomal MD-2, probably only after LPS internalization. With the exception of the MD-2 phosphorylation, Lyn is likely to interact with other proteins and catalyze phosphorylation of its substrates at the plasma membrane. In all the cases mentioned above, Lyn activity stimulates the respective events of LPS-induced signaling pathways (Fig. 4, left). This, however, is not the only mode of Lyn participation in the signaling.

Lyn kinase as a negative regulator of TLR4 signaling pathway

Lyn kinase is unique among the Src family kinases as it exerts both positive and negative regulatory action toward diverse signaling pathways [143, 146]. It has also been reported to act as a negative regulator of TLR4 signaling [147]. The studies were sparked by the finding that bone marrow-derived macrophages isolated from $l y n^{-1-}$ mice and stimulated with ReLPS produced more IL-6, TNF- $\alpha$, and IFN- $\alpha / \beta$ than their wild-type counterparts. In agreement with those ex vivo studies, increased amounts of TNF- $\alpha$, IL6 , and IFN- $\alpha / \beta$ were also found in the serum of $l y n^{-1-}$ mice injected with ReLPS. Those results indicated that Lyn is involved in the downregulation of both the MyD88- and TRIF-dependent pathways of TLR4. In search for the mechanism of the suppressory action of Lyn it was established that PI3-kinase and Akt kinase could be downstream targets of Lyn. It was inferred that the activity of PI3-kinase in LPS-stimulated cells led to phosphorylation of $\mathrm{PI}(4,5) \mathrm{P}_{2}$ to $\mathrm{PI}(3,4,5) \mathrm{P}_{3}$ in the plasma membrane and subsequent activation of Akt kinase. The latter was suggested to be responsible for the down-regulation of $\mathrm{p} 38$ phosphorylation eventually leading to decreased production of cytokines [147]. These data put PI3-kinase in a position of a negative regulator of TLR4 signaling (Fig. 4, right). Corroborating these results, wortmannin, a PI3-kinase inhibitor, augmented TNF- $\alpha$ and IL- 6 production while a lack of SHIP1 phosphatase which dephosphorylates $\mathrm{PI}(3,4,5) \mathrm{P}_{3}$ had an opposite effect. Recently, a contribution of PI3-kinase(s) to negative regulation of TLR4 pro-inflammatory signaling through the Akt-mTOR-Foxo1 signaling axis has been shown [148].

The association of Lyn with PI3-kinase(s) was described a decade earlier in LPS-stimulated human monocytes [149]. The enzymes co-immunoprecipitated and became activated in a coordinated manner within minutes of LPS action. Also, the level of $\mathrm{PI}(3,4,5) \mathrm{P}_{3}$ increased markedly in LPS-treated cells, as found by analyzing $\mathrm{P}^{32}$-labeled lipid extracts by HPLC. Of note neutralizing CD14 with a specific antibody abrogated this LPS-induced $\mathrm{PI}(3,4,5) \mathrm{P}_{3}$ production which indicated that CD14 and Lyn, two raftenriched proteins, regulate PI3-kinase involvement and $\mathrm{PI}(3,4,5) \mathrm{P}_{3}$ production in LPS-induced signaling.
There is a possible functional link between the CD14 involvement in LPS-induced signaling and $\mathrm{PI}(3,4,5) \mathrm{P}_{3}$ production, as both control the endocytosis of TLR4. Expression of a kinase-dead p110 isoform of the catalytic domain of PI3-kinase in mice inhibited LPS-induced endocytosis of TLR4 in bone marrow-derived dendritic cells [106]. The p110 $\delta$ defect downregulated TRIFdependent signaling and led to lower IFN- $\alpha$, IP-10, and RANTES production with concomitant augmentation of MyD88/TIRAP-mediated signaling detected both in the mice and in the bone marrow-derived dendritic cells. The inhibition on TRIF-dependent signaling caused by the lack of the activity of p110 $\delta$ isoform of PI3-kinase resembled that caused by the lack of CD14 in cells [28] but not the effects seen in Lyn-deficient macrophages where both MyD88- and TRIF-dependent signaling pathways of TLR4 were upregulated [147]. This indicates that proteins other

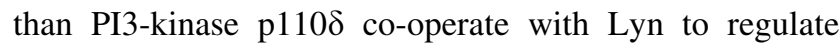
negatively both signaling pathways of TLR4.

Indeed, Lyn can exert its negative regulatory function by affecting many other proteins beside PI3-kinases. The list includes $\mathrm{Cbp} / \mathrm{PAG}$, a raft protein which is phosphorylated by Lyn and binds Csk kinase responsible for inactivation of Src family kinases [129]. Lyn also has a unique ability to phosphorylate the immunoreceptor tyrosine-base inhibitory motif (ITIM) of plasma membrane receptors such as Fc $\gamma$ RIIb, paired immunoglobulin-like receptor B (PIR-B), signal regulatory protein- $\alpha$ (SIRP $\alpha)$, and CD22. These phosphorylated proteins recruit inhibitory phosphatases, such as protein phosphatase SHP-1/2 and SHIP1, a phosphatase of $\mathrm{PI}(3,4,5) \mathrm{P}_{3}[150]$. The latter enzyme does not seem to contribute to the Lyn-dependent negative regulation of TLR4 signaling [147] while other possibilities have not been examined in this context. However, the inhibitory role of Fc $\gamma$ RIIb in TLR4-mediated responses was indicated [151].

In summary, the involvement of Lyn in LPS-induced signaling has both a positive role and generates a negative loop switching off the signaling (Fig. 4). Such a dual role of Lyn has been established previously for BCR and FceRI signaling in mast cells. The positive versus negative action of Lyn in FceRI-triggered signaling can depend on the intensity of stimulation of the receptor [152]. On the other hand, during activation of BCR, the two functions of Lyn need to be finely balanced and factors which determine the final outcome of Lyn activity are ill-defined, as both Lyn knockout mice and $\mathrm{Lyn}^{\text {up/up }}$ mice expressing constitutively active Lyn develop autoimmune diseases related to B-cell dysfunction [146]. Of special interest is that the positive role of Lyn detected in TLR4 signaling in mast cells contrasted with its negative role in TLR4 signaling in macrophages, since both series of experiments were performed on cells isolated form Lyn-deficient mice [140, 
147]. Furthermore, in macrophages, a triple knockout of Hck, Fgr, and Lyn facilitated production of some cytokines [132]. These data suggest that the final outcome of the Lyn involvement in TLR4-triggered signaling could be cell type-specific and depend, e.g., on the receptors complexing with TLR4, like CD14 or CD36 (see below) or Fc $\gamma$ receptors [29, 31, 153]. Taking into account that macrophages express CD14 at a high level while mast cells are CD14-deficient, it is tempting to speculate that if raftresiding CD14 is engaged in LPS-induced signaling, the negative regulatory function of Lyn rather than its indispensability for TLR4 signaling is emphasized. It is also plausible that Lyn regulates positively or negatively distinct components of TLR4 signaling pathways in a single cell type, resembling the Lyn involvement in BCR signaling [146]. Thus, Lyn could provide a subtle regulation of the amplitude and duration of the pro-inflammatory signaling triggered by LPS.

\section{Involvement of acid sphingomyelinase and other enzymes of sphingomyelin cycle in LPS-induced signaling}

The accumulation of acid sphingomyelinase (ASMase) in the DRM fraction of RAW264 cells within 5-30 min of LPS treatment [84] points to the importance of sphingomyelin turnover in LPS-induced signaling. About half of the cellular pool of sphingomyelin is that in the plasma membrane, 80-90\% of which resides in the outer leaflet of the membrane and is enriched in rafts $[154,155]$. Under the action of sphingomyelinases, sphingomyelin is hydrolyzed yielding ceramide, a multifaceted lipid which significantly changes the organization of the plasma membrane, affects the activity of several intracellular enzymes and is a precursor of other bioactive lipids, like ceramide-1-phosphate and sphingosine-1-phosphate $[154,156]$. The generation of ceramide in the outer leaflet of the plasma membrane is linked with the activity of ASMase which translocates to the cell surface from intracellular compartments in response to diverse stimuli. Hydrolysis of sphingomyelin in the inner leaflet of the membrane is attributed to the activity of neutral sphingomyelinase (NSMase) [156-158]. ASMase and NSMase are activated rapidly in J774 and THP-1 cells under the action of LPS [83, 159, 160]. The production of ceramide by sphingomyelin hydrolysis in LPS-treated cells is also rapid, within minutes [160, 161], and is distinct from the TLR4-dependent de novo ceramide synthesis leading to prolonged ceramide accumulation observed in chronic diseases [162].

The data on the role of ASMase and ceramide in LPSinduced signaling are contradictory. Early studies indicated some similarities between LPS and exogenous ceramides, including long-chain ones, or ceramide generated in cells upon treatment with bacterial sphingomyelinase, in inducing the assembly of multimolecular complexes in the plasma membrane, activation of MAP kinases and production of selected cytokines in various cells, including RAW264 cells and murine macrophages [29, 161, 163, 164]. Furthermore, a positive role of endogenous ceramide generated by ASMase in the pro-inflammatory responses of cells to LPS was indicated. The ceramide was required for LPS-induced recruitment of TLR4 to rafts, activation of MAP kinases and TNF- $\alpha$ production in differentiated THP-1 cells, as all these events were inhibited by imipramine, a drug causing ASMase degradation, and were reversed by exogenous $\mathrm{C} 2$-ceramide [83]. In agreement, inhibition of ASMase by the SMA-7 drug prevented NFKB activation and release of pro-inflammatory mediators in THP-1 cells [159]. Recently, a positive influence of ASMase-generated ceramide on IL-6 production by RAW 264 cells after prolonged stimulation by low doses of LPS (1 ng/ml) and palmitic acid was found [165].

In contrast, studies performed on ASMase knockout mouse or murine macrophages and J774 cells after ASMase or NSMase silencing indicated that ceramide generated in LPS-stimulated cells downregulates the production of TNF- $\alpha$ and other cytokines [160, 166]. In accordance, infection of the ASMase-deficient mice with Gram-negative bacterium Pseudomonas aeruginosa resulted in a roughly tenfold higher release of pro-inflammatory cytokine IL-1 $\beta$ than in wild-type mice, and their death [167]. Exogenous C8-ceramide was found to inhibit production of pro-inflammatory cytokines, TNF- $\alpha$, IL-6, and IL-12p40, by murine macrophages and pro-asthmatic IL-5, IL-10, and IL-13 by mast cells [168]. Accordingly, in a murine model of LPS- or Staphylococcus aureus-induced corneal inflammation, topical delivery of low doses of C6-ceramide in liposome formulation had a therapeutic effect supporting the anti-inflammatory properties of ceramide [169].

Ceramide generated in the outer leaflet of the plasma membrane can be converted back to sphingomyelin by sphingomyelin synthases 2 (SMS2) located in plasma membrane rafts/caveolae [156]. An impact of the SMS2 activity in the plasma membrane on pro-inflammatory signaling is yet to be proven unequivocally. Recent data indicate that in SMS2-deficient macrophages, enriched in ceramide and depleted in sphingomyelin, $\mathrm{NF \kappa B}$ activation was attenuated and LPS-induced lung injury reduced [170, 171]. In SMS2-deficient mice, the serum level of IL-6 and TNF- $\alpha$ was lower compared to their wild-type counterparts [172]. These data underscore the anti-inflammatory outcome of changing the sphingomyelin/ceramide balance in the plasma membrane in favor of ceramide.

The molecular mechanisms of the action of the ASMase-generated ceramide in LPS-stimulated cells are not 
completely understood and their revealing is hindered by the fact that exogenous short-chain ceramides do not necessarily mimic the action of endogenous ceramides acylated with long-chain fatty acids which are produced by ASMase. It is known that the exofacial ceramide generated by ASMase dramatically alters the biophysical properties of the plasma membrane [154]. Ceramide molecules separate laterally into domains, thereby displacing cholesterol form rafts [173] and affecting the lateral distribution of plasma membrane proteins. For example, ceramide was found to facilitate clustering of Fc $\gamma$ RII and CD95 in rafts $[157,174]$. Following this scenario, one can assume that ceramide generated by ASMase in LPS-stimulated cells promotes mobilization of TLR4 to rafts and facilitates the CD14-TLR4 interaction leading to activation of proinflammatory signaling. Accordingly, binding of LPS to CD14 was found to be required for ceramide generation in THP-1 cells [83]. The ability of ceramide to induce redistribution of plasma membrane proteins most likely accounts for the observed recruitment of selected cell surface proteins toward CD14 creating conditions for activation of selected signaling pathways in cells exposed to exogenous ceramides [29, 163].

The above scenario is in contrast with reports indicating a negative influence of ASMase-generated ceramide on the production of pro-inflammatory mediators, like TNF- $\alpha$ $[160,166]$. The ceramide inhibited maturation of TNF- $\alpha$ at the stage of the cleavage of TNF- $\alpha$ precursor to its active $17-\mathrm{kDa}$ soluble form by the TNF- $\alpha$ converting enzyme (TACE) [166], which also associated with rafts [175]. The ceramide negatively regulated TACE activity, which was tentatively linked with changes of TACE partitioning to rafts in ASMase-deficient cells. In addition, ASMase-generated ceramide could also affect cellular trafficking of the TNF- $\alpha$ precursor [166]. The mechanisms of the negative influence of ceramide on the production of other cytokines in LPS-stimulated cells are unknown, albeit inhibition of the LPS-induced activity of NFKB and AP- 1 by exogenous C-2 ceramide has been reported in RAW264 cells [176]. Possibly, the impact of the ASMase-generated ceramide on the associations of TLR4 with rafts also needs further studies. The shift of the balanced from sphingomyelin toward ceramide in the plasma membrane seems to negatively affect the association of TNF- $\alpha$ receptor with rafts [170]. Bearing in mind the positive effect of ceramide on the association of Fc $\gamma$ RII and CD95 with rafts, the lipid seems to be able to both facilitate and hinder the partition of various receptors to rafts. In accordance, recent studies on transferrin receptor ligated with transferrin indicated that ASMase-generated ceramide inhibited receptor partitioning to rafts and facilitated its endocytosis by clathrincoated pits [177]. The latter is in agreement with the ability of exofacial ceramide to induce inward curvature of the plasma membrane and subsequent budding of endocytic vesicles [178]. Taking into account, the dynamic association of TLR4 with rafts followed by its endocytosis in LPSstimulated cells, one can expect a complex impact of sphingomyelin/ceramide turnover on the receptor translocations in the plasma membrane which could change in the course of TLR4 activation. Such complexity could account for the discrepant effects of the interference with the turnover of sphingomyelin in LPS-stimulated cells.

\section{Proteasome as newly identified raft component involved in LPS signaling}

A recent proteomic analysis has revealed that following LPS action, numerous proteins involved in protein ubiquitination and several proteasome subunits are recruited to the DRM fraction of RAW264 cells [84]. Furthermore, p105 protein was identified as a proteasomal substrate in the DRM fraction of LPS-stimulated cells. Degradation of this protein releases Tpl2 kinase which phosphorylates MEK and leads to ERK activation, and both phosphorylated MEK and ERK kinases were found to be confined to the DRM fraction of RAW264 cells [84, 117]. Thus, these studies suggest that the plasma membrane rafts are sites of the activity of proteasomes linked to ERK activation in LPS-stimulated cells. It has also been shown that LPS alters the composition of proteasomes, and that proteasomal degradation of several signaling proteins regulates both MyD88- and TRIF-dependent generation of proinflammatory mediators [179], with the proteolysis of IKB by $26 \mathrm{~S}$ proteasome being the best characterized. Remarkably, $26 \mathrm{~S}$ proteasome is activated by LPS in the DRM fraction of RAW264 cells [84]. Proteasome activity is a novel function linked to rafts and further studies are required to reveal how proteasomes associate with the plasma membrane and are activated in LPS-stimulated cells.

\section{Involvement of CD44 and Hsp70 in TLR4 signaling triggered by LPS and non-microbial ligands}

CD44, the hyaluronan receptor, is another raft protein likely to co-operate with TLR4. This co-operation regulates the pro-inflammatory responses induced by LPS and also those observed in the absence of microbial stimuli. During trauma fragments of hyaluronan are released from the extracellular matrix and, after binding to CD44, induce expression of pro-inflammatory genes in a TLR4/MD-2dependent manner. Only some of these genes are those activated by LPS as well, as shown in vivo by studying skin samples of sterile-injured mice [180]. In those studies, 
CD44 was identified as an important intermediate in the hyaluronan-induced TLR4 activation. However, in the presence of microbial PAMPs, CD44 negatively regulates cytokine production: macrophages derived form $C d 44^{-1-}$ mice and exposed to LPS or ligands for TLR2, TLR3, TLR6, TLR8, or TLR9 produced more cytokines compared with $C d 44^{+/+}$cells [181]. In agreement with those molecular data, CD44-deficient mice were more susceptible to LPS-induced shock $[182,183]$. The protective role of CD44 against excessive inflammatory responses to LPS was ascribed to expression of negative regulators of TLR4 signaling, IRAK-M, Toll-interacting protein, and AD20 [182, 183]. Hyaluronan also acts through TLR4 to inhibit TLR3-dependent inflammation [184].

Hyaluronan is one of alarmins or DAMPs (damageassociated molecular patterns), endogenous molecules released from injured or dead cells and activating pattern recognition receptors for production of pro-inflammatory mediators in a similar manner as PAMPs do. This class of molecules also includes heat shock proteins [185]. After exposure of cells to a stress even without LPS stimulation, cytoplasmic Hsp70 incorporates into the plasma membrane in the raft region judging from its partition to the DRM fraction. The protein spans the membrane exposing only a small portion of its C-terminus to the cell exterior and is released in the membrane-bound form by exocytosis or membrane shedding. When reintroduced into J774 cell culture such membrane-associated Hsp70 induces production of TNF- $\alpha$ [186]. Soluble Hsp70 can also associate with/incorporate in the plasma membrane of macrophages with a preference toward the DRM fraction and stimulate phagocytosis [187], but its ability for TNF- $\alpha$ induction is much weaker than that of the membrane-bound form [186]. The Hsp70-bearing membranes used in those studies were prepared from eukaryotic HepG2 cells; therefore, the proinflammatory activity observed can safely be ascribed to Hsp70 itself rather than to contaminating microbial components, as suggested earlier [188]. Notably, the relation between Hsp70 and TLR4 activity was not addressed in the above studies. However, preincubation of THP-1 cells with Hsp70 reduced the NFKB activation by subsequent LPS treatment, an effect known as endotoxin tolerance, which indicates a cross-talk between the signaling cascades triggered by the DAMP and PAMP [189].

The participation of Hsp70 in LPS-triggered proinflammatory responses is supported by a diversified line of data. In LPS-stimulated cells, Hsp70 and Hsp90 were among the few proteins found in close proximity to GM1 and TLR4 in the plasma membrane by FRET analysis, and accumulated together with TLR4 in the DRM fraction [33, 69, 190]. LPS and the febrile-range temperature that accompanies first days of sepsis induced Hsp70 expression and its release outside RAW264 cells. Concomitant exposure of mice to febrile-range hyperthermia and intratracheal administration of LPS also caused an elevation of Hsp70 in a cell-free lung lavage greater than hyperthermia or LPS alone [191]. It has been also demonstrated that Hsp70 and Hsp90 bind LPS [33]. The interaction of Hsp70 and Hsp90 with LPS, and possibly also with lipopeptides, is probably mediated by the hydrophobic interactions that otherwise facilitate the interactions of the Hsp with their substrate proteins. Thus, it seems likely that Hsp70 acts as an LPS/lipoprotein acceptor donating them to TLR4 or TLR2 and inducing production of pro-inflammatory mediators after incorporation into plasma membrane rafts. It has been also hypothesized that rafts can serve as platform which govern phagocytosis triggered by Hsp70 [187], leaving an open question of a possible contribution of this process to the pro-inflammatory activity of Hsp70.

\section{CD36, a newly discovered player in TLR4 signaling triggered by non-microbial ligands}

CD36, a class B scavenger receptor, is a plasma membrane protein of an unusual hairpin-like structure with both its $\mathrm{N}$ and C-termini directed toward the cytoplasm and connected by a large extracellular ligand-binding loop. The both cytoplasmic tails of CD36 are palmitoylated, which modification facilitates the association of CD36 with rafts isolated as the DRM fraction $[55,56]$. Those early studies indicated also that CD36 associates with Lyn kinase in rafts, and this interaction has recently been proven to be pivotal for controlling TLR signaling triggered by ligands of endogenous origin [153]. After recognition of oxidized low-density lipoprotein (oxLDL) or $\beta$-amyloid, CD36 undergoes phosphorylation on C-terminal $\mathrm{Tyr}^{436}$ and associates with Lyn, thereby inducing formation of a heterotrimeric complex of CD36, TLR4, and TLR6. Once clustered, TLR4/TLR6 trigger signaling pathways which engage MyD88 and TRIF, activate inflammasome and induce production of an array of pro-inflammatory mediators. Signaling from the CD36/TLR4/TLR6 complex requires dynamin-mediated endocytosis. This is in agreement with studies showing that CD36-mediated endocytosis provides the major route for the oxLDL uptake by human and mouse macrophages [120, 192]. The molecular mechanisms of CD36-induced internalization are divergent but the prevailing one has been characterized by Heit et al. [120], and discussed above as a possible model of CD14-mediated uptake of TLR4/LPS. The apparent link between CD36 activity and endocytosis which controls signaling of the TLR4/TLR6 complex recalls the participation of CD14 in endocytosis of TLR4 which governs TRIF-dependent signaling in LPS-stimulated cells. The mechanism of the cross-talk among CD36, 
Lyn, TLR4, and TLR6 remains unknown; however, the involvement of CD36 and Lyn indicates a raft-based regulation of these events [153]. Of note, that newly detected link between CD36 and TLR4/TLR6 activity was described in microglia and monocytes/macrophages activated not by microbial PAMPs but by endogenous ligands [153, 193] whose accumulation is a hallmark of atherosclerosis and Alzheimer's disease.

CD36 also participates in the recognition of microbial PAMPs. It is a multipurpose protein which binds and mediates internalization of Gram-positive and Gram-negative bacteria as well as LPS [35, 194, 195]. Human CD36 can activate JNK1/2 kinase and IL- 8 production in cells exposed to LPS or E. coli independently of TLR4 [195]. Therefore, the action of LPS as a possible contaminant in oxLDL samples needs to be considered when studying the pro-inflammatory activity of oxLDL, as indicated recently by Kannan et al. [196]. A line of data indicates that the protein functions also as a co-receptor which delivers other bacterial components to TLRs. CD36 serves as an acceptor of lipoteichoic acid and diacylated peptides and subsequently associates with TLR2/TLR6 complex, likely using rafts as regulators of the CD36-TLR2-TLR6 proximity [197]. A complex of CD36, TLR2/TLR1, and CD11/CD18 likely formed in rafts has been shown to mediate proinflammatory responses to the tetra- or penta-acylated LPS chemotypes which do not activate TLR4 [198]. The proinflammatory reaction to these ligands can be further upregulated by the presence of oxLDL [199]. Taken together, the data indicate that CD36 binds distinct "self-" and "non-self" ligands and contributes to activation of diverse TLRs and other co-receptors. Both the raft localization and the endocytic activity of CD36 seem crucial for its involvement in TLR signaling pointing to similarities between functioning of CD36 and CD14.

\section{Concluding remarks}

Ample data point to the importance of raft integrity for proinflammatory TLR4 signaling. These include the disturbances of the signaling caused by manipulation of the cholesterol level in the plasma membrane or by interference in the sphingomyelin/ceramide balance. Furthermore, several cell surface proteins accumulated in plasma membrane rafts, like CD14, CD44, and CD36 participate in the recognition of LPS and non-microbial components which subsequently activate TLR4. Others, like Lyn kinase anchored in the inner leaflet of the rafts, are involved in TLR4-triggered signaling cascades. Surprisingly, the importance of the raft localization of these proteins for their involvement in TLR4 signaling has only rarely been addressed. A common feature of the CD14 and CD36 engagement in TLR4-induced signaling is their contribution to the internalization of activated TLR4 and TLR4/ TLR6. This suggests that the endocytosis of the receptors could be a major phenomenon governed by raft-associated proteins during stimulation of cells with LPS or nonmicrobial components activating TLR4. Rafts can serve as platforms clustering together a group of proteins, like ITAM-containing proteins, Lyn and Syk kinases, and PLC $\gamma 2$ controlling the uptake of TLR4 to trigger the TRIFdependent signaling pathway.

Acknowledgments This work was supported by Grant 2013/08/A/ NZ3/00850 from the National Science Centre, Poland. We gratefully thank Prof. Andrzej Sobota, Nencki Institute of Experimental Biology, Warsaw, for support and discussion. We also thank Prof. Jan Fronk, Warsaw University, and anonymous reviewers for valuable comments on the manuscript.

Open Access This article is distributed under the terms of the Creative Commons Attribution License which permits any use, distribution, and reproduction in any medium, provided the original author(s) and the source are credited.

\section{References}

1. O'Neill LA, Bryant CE, Doyle SL (2009) Therapeutic targeting of Toll-like receptors for infectious and inflammatory diseases and cancer. Pharmacol Rev 61:177-197

2. den Dekker WK, Cheng C, Pasterkamp G, Duckers HJ (2010) Toll like receptor 4 in atherosclerosis and plaque destabilization. Atherosclerosis 209:314-320

3. Trotta T, Porro C, Calvello R, Panaro MA (2014) Biological role of Toll-like receptor-4 in the brain. J Neuroimmunol 268:1-12

4. Poltorak A, He X, Smirnova I, Liu MY, Van Huffel C, Du X, Birdwell D, Alejos E, Silva M, Galanos C, Freudenburg M, Ricciardi-Castagnoli P, Layton B, Beutler B (1998) Defective LPS signaling in $\mathrm{C} 3 \mathrm{H} / \mathrm{HeJ}$ and $\mathrm{C} 57 \mathrm{BL} / 10 \mathrm{ScCr}$ mice: mutations in Tlr4 gene. Science 282:2085-2088

5. Beutler B, Du X, Poltorak A (2001) Identification of Toll-like receptor 4 (Tlr4) as the sole conduit for LPS signal transduction: genetic and evolutionary studies. J Endotoxin Res 7:277-280

6. Liu L, Botos I, Wang Y, Leonard JN, Shiloach J, Segal DM, Davies DR (2008) Structural basis of Toll-like receptor 3 signaling with double-stranded RNA. Science 320:379-381

7. Kang JY, Nan X, Jin MS, Youn S-J, Ryu YH, Mah S, Han SH, Lee H, Paik SG, Lee JO (2009) Recognition of lipopeptide patterns by Toll-like receptor 2-Toll-like receptor 6 heterodimer. Immunity $31: 873-884$

8. Park BS, Song DH, Kim HM, Choi BS, Lee H, Lee JO (2009) The structural basis of lipopolysaccharide recognition by the TLR4-MD-2 complex. Nature 458:1191-1195

9. Xu Y, Tao X, Shen B, Horng T, Medzhitov R, Manley JL, Tong L (2000) Structural basis for signal transduction by the toll/ interleukin-1 receptor domains. Nature 408:111-115

10. Yu B, Wright SD (1996) Catalytic properties of lipopolysaccharide (LPS) binding protein. Transfer of LPS to soluble CD14. J Biol Chem 271:4100-4105

11. Iovine N, Eastvold J, Elsbach P, Weiss JP, Gioannini TL (2002) The carboxyl-terminal domain of closely related endotoxinbinding proteins determines the target of protein-lipopolysaccharide complexes. J Biol Chem 277:7970-7978 
12. Goyert SM, Ferrero E, Rettig WJ, Yenamandra AK, Obata F, Beau MML (1988) The CD14 monocyte differentiation antigen maps to a region encoding growth factors and receptors. Science 239:497-500

13. Simmons DL, Tan S, Tenen DG, Nicholson-Weller A, Seed B (1989) Monocyte antigen CD14 is a phospholipid anchored membrane protein. Blood 73:284-289

14. Kim J-I, Lee CJ, Jin MS, Lee CH, Paik SG, Lee H, Lee JO (2005) Crystal structure of CD14 and its implications for lipopolysaccharide signaling. J Biol Chem 280:11347-11351

15. Kelley SL, Lukk T, Nair SK, Tapping RI (2013) The crystal structure of human soluble CD14 reveals a bent solenoid with a hydrophobic amino-terminal pocket. J Immunol 190:1304-1311

16. Gioannini TL, Zhang D, Teghanemt A, Weiss JP (2002) An essential role for albumin in the interaction of endotoxin with lipopolysaccharide-binding protein and SCD14 and resultant cell activation. J Biol Chem 277:47818-47825

17. Da Silva Correia J, Soldau K, Christen U, Tobias PS, Ulevitch RJ (2001) Lipopolysaccharide is in close proximity to each of the proteins in its membrane receptor complex transfer from CD14 to TLR4 and MD-2. J Biol Chem 276:21129-21135

18. Gioannini TL, Teghanemt A, Zhang D, Coussens NP, Dockstader W, Ramaswamy S, Weiss JP (2004) Isolation of an endotoxin-MD-2 complex that produces Toll-like receptor 4-dependent cell activation at picomolar concentrations. Proc Natl Acad Sci USA 101:4186-4191

19. Gioannini TL, Teghanemt A, Zhang D, Levis EN, Weiss JP (2005) Monomeric endotoxin:protein complexes are essential for TLR4-dependent cell activation. J Endotoxin Res 11:117-123

20. Nagai Y, Akashi S, Nagafuku M, Ogata M, Iwakura Y, Akira S, Kitamura T, Kosugi A, Kimoto M, Miyake K (2002) Essential role of MD-2 in LPS responsiveness and TLR4 distribution. Nat Immunol 3:667-672

21. Ohto U, Fukase K, Miyake K, Satow Y (2007) Crystal structures of human MD-2 and its complex with antiendotoxic lipid IVa. Science 316:1632-1634

22. Resman N, Vasl J, Oblak A, Pristovsek P, Gioannini TL, Weiss JP, Jerala R (2009) Essential roles of hydrophobic residues in both MD-2 and Toll-like receptor 4 in activation by endotoxin. J Biol Chem 284:15052-15060

23. Motshwene PG, Moncrieffe MC, Grossmann JG, Kao C, Ayaluru M, Sandercock AM, Carol V, Robinson C, Latz E, Gay NJ (2009) An oligomeric signaling platform formed by the Toll-like receptor signal transducers MyD88 and IRAK-4. J Biol Chem 284:25404-25411

24. Lin S-C, Lo Y-C, Wu H (2010) Helical assembly in the MyD88IRAK4-IRAK2 complex in TLR/IL-1R signalling. Nature 465:885-890

25. Kawai T, Akira S (2011) Toll-like receptors and their crosstalk with other innate receptors in infection and immunity. Immunity 34:637-650

26. Husebye H, Halaas O, Stenmark H, Tunheim G, Sandanger O, Bogen B, Brech A, Latz E, Espevik T (2006) Endocytic pathways regulate Toll-like receptor 4 signaling and link innate and adaptive immunity. EMBO J 25:683-692

27. Kagan JC, Su T, Horng T, Chow A, Akira S, Medzhitov R (2008) TRAM couples endocytosis of Toll-like receptor 4 to the induction of interferon- $\beta$. Nat Immunol 9:361-368

28. Zanoni I, Ostuni R, Marek LR, Barresi S, Barbalat R, Barton GM, Granucci F, Kagan JC (2011) CD14 controls the LPSinduced endocytosis of Toll-like receptor 4. Cell 147:868-880

29. Pfeiffer A, Böttcher A, Orso E, Kapinsky M, Nagy P, Bodnar A, Spreitzer I, Liebisch G, Drobnik W, Gempel K, Horn M, Holmer S, Hartung T, Multhoff G, Schütz G, Schindler H, Ulmer AJ, Heine H, Stelter F, Schütt C, Rothe G, Szollosi J, Damjanovich
S, Schmitz G (2001) Lipopolysaccharide and ceramide docking to $\mathrm{CD} 14$ provokes ligand-specific receptor clustering in rafts. Eur J Immunol 31:3153-3164

30. Heine H, El-Samalouti VT, Nötzel C, Pfeiffer A, Lentschat A, Kusumoto S, Schmitz G, Hamann L, Ulmer AJ (2003) CD55/ decay accelerating factor is part of the lipopolysaccharideinduced receptor complex. Eur J Immunol 33:1399-1408

31. Triantafilou M, Brandenburg K, Kusumoto S, Fukase K, Mackie A, Seydel U, Triantafilou K (2004) Combinational clustering of receptors following stimulation by bacterial products determines lipopolysaccharide responses. Biochem J 381:527-536

32. Yu H, Ha T, Liu L, Wang X, Gao M, Kelley J, Kao R, Williams D, Li C (2012) Scavenger receptor A (SR-A) is required for LPS-induced TLR4 mediated NF- $\kappa B$ activation in macrophages. Biochim Biophys Acta 1823:1192-1198

33. Triantafilou K, Triantafilou M, Dedrick RL (2001) A CD14independent LPS receptor cluster. Nat Immunol 2:338-345

34. Triantafilou M, Lepper PM, Briault CD, Ahmed MA, Dmochowski JM, Schumann C, Triantafilou K (2008) Chemokine receptor 4 (CXCR4) is part of the lipopolysaccharide "sensing apparatus". Eur J Immunol 38:192-203

35. Baranova IN, Vishnyakova TG, Bocharov AV, Leelahavanichkul A, Kurlander R, Chen Z, Souza AC, Yuen PS, Star RA, Csako G, Patterson AP, Eggerman TL (2012) Class B scavenger receptor types I and II and CD36 mediate bacterial recognition and proinflammatory signaling induced by Escherichia coli, lipopolysaccharide, and cytosolic chaperonin 60 . J Immunol 188:1371-1380

36. Czerkies M, Borzęcka K, Zdioruk MI, Płóciennikowska A, Sobota A, Kwiatkowska K (2013) An interplay between scavenger receptor A and CD14 during activation of $\mathrm{J} 774$ cells by high concentrations of LPS. Immunobiology 218:1217-1226

37. Hagar JA, Powell DA, Aachoui Y, Ernst RK, Miao EA (2013) Cytoplasmic LPS activates caspase-11: implications in TLR4independent endotoxic shock. Science 341:1250-1253

38. Kayagaki N, Wong MT, Stowe IB, Ramani SR, Gonzalez LC, Akashi-Takamura S, Miyake K, Zhang J, Lee WP, Muszyński A, Forsberg LS, Carlson RW, Dixit VM (2013) Noncanonical inflammasome activation by intracellular LPS independent of TLR4. Science 341:1246-1249

39. Shi J, Zhao Y, Wang Y, Gao W, Ding J, Li P, Hu L, Shao F (2014) Inflammatory caspases are innate immune receptors for intracellular LPS. Nature 514:187-192

40. Coll RC, O'Neill LAJ (2010) New insights into the regulation of signalling by Toll-like receptors and nod-like receptors. J Innate Immun 2:406-421

41. Hancock JF (2006) Lipid rafts: contentious only from simplistic standpoints. Nat Rev Mol Cell Biol 7:456-462

42. Lingwood D, Simons K (2010) Lipid rafts as a membraneorganizing principle. Science 327:46-50

43. Simons K, Ikonen E (1997) Functional rafts in cell membranes. Nature 387:569-572

44. Brown RE (1998) Sphingolipid organization in biomembranes: what physical studies of model membranes reveal. J Cell Sci 111:1-9

45. Ahmed SN, Brown DA, London E (1997) On the origin of sphingolipid/cholesterol-rich detergent-insoluble cell membranes: physiological concentrations of cholesterol and sphingolipid induce formation of a detergent-insoluble, liquid-ordered lipid phase in model membranes. Biochemistry 36:10944-10953

46. Veiga MP, Arrondo JL, Goñi FM, Alonso A, Marsh D (2001) Interaction of cholesterol with sphingomyelin in mixed membranes containing phosphatidylcholine, studied by spinlabel ESR and IR spectroscopies. A possible stabilization of gelphase sphingolipid domains by cholesterol. Biochemistry 40:2614-2622 
47. Lingwood D, Ries J, Schwille P, Simons K (2008) Plasma membranes are poised for activation of raft phase coalescence at physiological temperature. Proc Natl Acad Sci USA 105:10005-10010

48. Kaiser H-J, Lingwood D, Levental I, Sampaio JL, Kalvodova L, Rajendran L, Simons K (2009) Order of lipid phases in model and plasma membranes. Proc Natl Acad Sci USA 106:16645-16650

49. Levental I, Grzybek M, Simons K (2011) Raft domains of variable properties and compositions in plasma membrane vesicles. Proc Natl Acad Sci USA 108:11411-11416

50. Baumgart T, Hammond AT, Sengupta P, Hess ST, Holowka DA, Baird BA, Webb WW (2007) Large-scale fluid/fluid phase separation of proteins and lipids in giant plasma membrane vesicles. Proc Natl Acad Sci USA 104:3165-3170

51. Sezgin E, Kaiser HJ, Baumgart T, Schwille P, Simons K, Levental I (2012) Elucidating membrane structure and protein behavior using giant plasma membrane vesicles. Nat Protoc 7:1042-1051

52. Benting J, Rietveld A, Ansorge I, Simons K (1999) Acyl and alkyl chain length of GPI-anchors is critical for raft association in vitro. FEBS Lett 462:47-50

53. Resh MD (2006) Palmitoylation of ligands, receptors, and intracellular signaling molecules. Sci STKE 359:re14

54. Łach A, Grzybek M, Heger E, Korycka J, Wolny M, Kubiak J, Kolondra A, Bogusławska DM, Augoff K, Majkowski M, Podkalicka J, Kaczor J, Stefanko A, Kuliczkowski K, Sikorski AF (2012) Palmitoylation of MPP1 (membrane-palmitoylated protein 1)/p55 is crucial for lateral membrane organization in erythroid cells. J Biol Chem 287:18974-118984

55. Dorahy DJ, Lincz LF, Meldrum CJ, Burns GF (1996) Biochemical isolation of a membrane microdomain from resting platelets highly enriched in the plasma membrane glycoprotein CD36. Biochem J 319:67-72

56. Tao N, Wagner SJ, Lublin DM (1996) CD36 is palmitoylated on both $\mathrm{N}$ - and C-terminal cytoplasmic tails. J Biol Chem 271:22315-22320

57. Brdicka T, Imrich $M$, Angelisová $P$, Brdicková $N$, Horváth $O$, Spicka J, Hilgert I, Lusková P, Dráber P, Novák P, Engels N, Wienands J, Simeoni L, Osterreicher J, Aguado E, Malissen M, Schraven B, Horejsí V (2002) Non-T cell activation linker (NTAL): a transmembrane adaptor protein involved in immunoreceptor signaling. J Exp Med 196:1617-1626

58. Thankamony SP, Knudson W (2006) Acylation of CD44 and its association with lipid rafts are required for receptor and hyaluronan endocytosis. J Biol Chem 281:34601-34609

59. Hrdinka M, Horejsi V (2013) PAG: a multipurpose transmembrane adaptor protein. Oncogene 33:4881-4892

60. Levental I, Lingwood D, Grzybek M, Coskun U, Simons K (2010) Palmitoylation regulates raft affinity for the majority of integral raft proteins. Proc Natl Acad Sci USA 107: 22050-22054

61. Diaz-Rohrer BB, Levental KR, Simons K, Levental I (2014) Membrane raft association is a determinant of plasma membrane localization. Proc Natl Acad Sci USA 111:8500-8505

62. Anderson RGW, Jacobson K (2002) A role for lipid shells in targeting proteins to caveolae, rafts, and other lipid domains. Science 296:1821-1825

63. Janes PW, Ley SC, Magee AI (1999) Aggregation of lipid rafts accompanies signaling via the $\mathrm{T}$ cell antigen receptor. $\mathrm{J}$ Cell Biol 147:447-461

64. Sheets ED, Holowka D, Baird B (1999) Critical role for cholesterol in Lyn-mediated tyrosine phosphorylation of FceRI and their association with detergent-resistant membranes. J Cell Biol $145: 877-887$
65. Kwiatkowska K, Frey J, Sobota A (2003) Phosphorylation of Fc $\gamma$ RIIA is required for the receptor-induced actin rearrangement and capping: the role of membrane rafts. J Cell Sci 116:537-550

66. Lajoie P, Nabi IR (2010) Lipid rafts, caveolae, and their endocytosis. Int Rev Cell Mol Biol 282:135-163

67. Cao X, Surma MA, Simons K (2012) Polarized sorting and trafficking in epithelial cells. Cell Res 22:793-800

68. Tsai TH, Chen SF, Huang TY, Tzeng CF, Chiang AS, Kou YR, Lee TS, Shyue SK (2011) Impaired Cd14 and CD36 expression, bacterial clearance, and Toll-like receptor 4-Myd88 signaling in caveolin-1-deleted macrophages and mice. Shock 35:92-99

69. Triantafilou M, Miyake K, Golenbock DT, Triantafilou K (2002) Mediators of innate immune recognition of bacteria concentrate in lipid rafts and facilitate lipopolysaccharide-induced cell activation. J Cell Sci 115:2603-2611

70. London E, Brown DA (2000) Insolubility of lipids in Triton X-100: physical origin and relationship to sphingolipid/cholesterol membrane domains (rafts). Biochim Biophys Acta 1508:182-195

71. Pike LJ (2004) Lipid rafts: heterogeneity on the high seas. Biochem J 378:281-292

72. Schuck S, Honsho M, Ekroos K, Shevchenko A, Simons K (2003) Resistance of cell membranes to different detergents. Proc Natl Acad Sci USA 100:5795-5800

73. Otáhal P, Angelisová P, Hrdinka M, Brdicka T, Novák P, Drbal K, Horejsí V (2010) A new type of membrane raft-like microdomains and their possible involvement in TCR signaling. J Immunol 184:3689-3696

74. Heerklotz H (2002) Triton promotes domain formation in lipid raft mixtures. Biophys J 83:2693-2701

75. Korzeniowski M, Kwiatkowska K, Sobota A (2003) Insights into the association of Fc $\gamma$ RII and TCR with detergent-resistant membrane domains: isolation of the domains in detergent-free density gradients facilitates membrane fragment reconstitution. Biochemistry 42:5358-5367

76. Owen DM, Gaus K (2013) Imaging lipid domains in cell membranes: the advent of super-resolution fluorescence microscopy. Front Plant Sci 4:503

77. Triantafilou M, Morath S, Mackie A, Hartung T, Triantafilou K (2004) Lateral diffusion of Toll-like receptors reveals that they are transiently confined within lipid rafts on the plasma membrane. J Cell Sci 117:4007-4014

78. Koseki M, Hirano K, Masuda D, Ikegami C, Tanaka M, Ota A, Sandoval JC, Nakagawa-Toyama Y, Sato SB, Kobayashi T, Shimada Y, Ohno-Iwashita Y, Matsuura F, Shimomura I, Yamashita S (2007) Increased lipid rafts and accelerated lipopolysaccharide-induced tumor necrosis factor- $\alpha$ secretion in Abca1-deficient macrophages. J Lipid Res 48:299-306

79. Yvan-Charvet L, Welch C, Pagler TA, Ranalletta M, Lamkanfi M, Han S, Ishibashi M, Li R, Wang N, Tall AR (2008) Increased inflammatory gene expression in $\mathrm{ABC}$ transporter-deficient macrophages: free cholesterol accumulation, increased signaling via Toll-like receptors, and neutrophil infiltration of atherosclerotic lesions. Circulation 118:1837-1847

80. Zhu X, Owen JS, Wilson MD, Li H, Griffiths GL, Thomas MJ, Hiltbold EM, Fessler MB, Parks JS (2010) Macrophage ABCA1 reduces MyD88-dependent Toll-like receptor trafficking to lipid rafts by reduction of lipid raft cholesterol. J Lipid Res 51:3196-3206

81. Wong SW, Kwon MJ, Choi AM, Kim HP, Nakahira K, Hwang DH (2009) Fatty acids modulate Toll-like receptor 4 activation through regulation of receptor dimerization and recruitment into lipid rafts in a reactive oxygen species-dependent manner. J Biol Chem 284:27384-27392

82. Huang S, Rutkowsky JM, Snodgrass RG, Ono-Moore KD, Schneider DA, Newman JW, Adams SH, Hwang DH (2012) 
Saturated fatty acids activate TLR-mediated proinflammatory signaling pathways. J Lipid Res 53:2002-2013

83. Cuschieri J, Bulger E, Billgrin J, Garcia I, Maier RV (2007) Acid sphingomyelinase is required for lipid Raft TLR4 complex formation. Surg Infect (Larchmt) 8:91-106

84. Dhungana S, Merrick BA, Tomer KB, Fessler MB (2009) Quantitative proteomics analysis of macrophage rafts reveals compartmentalized activation of the proteasome and of proteasome-mediated ERK activation in response to lipopolysaccharide. Mol Cell Proteomics 8:201-213

85. Kleveta G, Borzęcka K, Zdioruk M, Czerkies M, Kuberczyk H, Sybirna N, Sobota A, Kwiatkowska K (2012) LPS induces phosphorylation of actin-regulatory proteins leading to actin reassembly and macrophage motility. J Cell Biochem 113:80-92

86. Ferrero E, Jiao D, Tsuberi BZ, Tesio L, Rong GW, Haziot A, Goyert SM (1993) Transgenic mice expressing human CD14 are hypersensitive to lipopolysaccharide. Proc Natl Acad Sci USA 90:2380-2384

87. Haziot A, Ferrero E, Kontgen F, Hijiya N, Yamamoto S, Silver J, Stewart CL, Goyert SM (1996) Resistance to endotoxin shock and reduced dissemination of gram-negative bacteria in CD14deficient mice. Immunity 4:407-414

88. Jiang Z, Georgel P, Du X, Shamel L, Sovath S, Mudd S, Huber M, Kalis C, Keck S, Galanos C, Freudenberg M, Beutler B (2005) CD14 is required for MyD88-independent LPS signaling. Nat Immunol 6:565-570

89. Zanoni I, Granucci F (2013) Role of CD14 in host protection against infections and in metabolism regulation. Front Cell Infect Microbiol 3:32

90. Fitzgerald KA, Rowe DC, Golenbock DT (2004) Endotoxin recognition and signal transduction by the TLR4/MD2-complex. Microbes Infect 6:1361-1367

91. Pugin J, Heumann ID, Tomasz A, Kravchenko VV, Akamatsu Y, Nishijima M, Glauser MP, Tobias PS, Ulevitch RJ (1994) CD14 is a pattern recognition receptor. Immunity 1:509-516

92. Pugin J, Schürer-Maly CC, Leturcq D, Leturcq D, Moriarty A, Ulevitch RJ, Tobias PS (1993) Lipopolysaccharide activation of human endothelial and epithelial cells is mediated by lipopolysaccharide-binding protein and soluble CD14. Proc Natl Acad Sci USA 90:2744-2748

93. Huber M, Kalis C, Keck S, Jiang Z, Georgel P, Du X, Shamel L, Sovath S, Mudd S, Beutler B, Galanos C, Freudenberg MA (2006) R-form LPS, the master key to the activation of TLR4/ MD-2-positive cells. Eur J Immunol 36:701-711

94. Perera PY, Vogel SN, Detore GR, Haziot A, Goyert SM (1997) CD14-dependent and CD14-independent signaling pathways in murine macrophages from normal and CD14 knockout mice stimulated with lipopolysaccharide or taxol. J Immunol 158:4422-4429

95. Gangloff SC, Zähringer U, Blondin C, Guenounou M, Silver J, Goyert SM (2005) Influence of CD14 on ligand interactions between lipopolysaccharide and its receptor complex. J Immunol 175:3940-3945

96. Zanoni I, Bodio C, Broggi A, Ostuni R, Caccia M, Collini M, Venkatesh A, Spreafico R, Capuano G, Granucci F (2012) Similarities and differences of innate immune responses elicited by smooth and rough LPS. Immunol Lett 142:41-47

97. Borzęcka K, Płóciennikowska A, Björkelund H, Sobota A, Kwiatkowska K (2013) CD14 mediates binding of high doses of LPS but is dispensable for TNF- $\alpha$ production. Mediators Inflam 2013:824919

98. Pupo E, Lindner B, Brade H, Schromm AB (2013) Intact roughand smooth-form lipopolysaccharides from Escherichia coli separated by preparative gel electrophoresis exhibit differential biologic activity in human macrophages. FEBS J 280: $1095-1111$
99. Esparza GA, Teghanemt A, Zhang D, Gioannini TL, Weiss JP (2012) Endotoxin:albumin complexes transfer endotoxin monomers to MD-2 resulting in activation of TLR4. Innate Immun 18:478-491

100. Mueller M, Lindner B, Kusumoto S, Fukase K, Schromm AB, Seydel U (2004) Aggregates are the biologically active units of endotoxin. J Biol Chem 279:26307-26313

101. Nomura K, Maeda M, Sugase K, Kusumoto S (2011) Lipopolysaccharide induces raft domain expansion in membrane composed of a phospholipid-cholesterol-sphingomyelin ternary system. Innate Immun 17:256-268

102. Kubiak J, Brewer J, Hansen S, Bagatolli LA (2011) Lipid lateral organization on giant unilamellar vesicles containing lipopolysaccharides. Biophys J 100:978-986

103. Alam JM, Yamazaki M (2011) Spontaneous insertion of lipopolysaccharide into lipid membranes from aqueous solution. Chem Phys Lipids 164:166-174

104. Ciesielski F, Davis B, Rittig M, Bonev BB, O'Shea P (2012) Receptor-independent interaction of bacterial lipopolysaccharide with lipid and lymphocyte membranes; the role of cholesterol. PLoS ONE 7:e38677

105. Tanimura N, Saitoh S, Matsumoto F, Akashi-Takamura S, Miyake K (2008) Roles for LPS-dependent interaction and relocation of TLR4 and TRAM in TRIF-signaling. Biochem Biophys Res Commun 368:94-99

106. Aksoy E, Taboubi S, Torres D, Delbauve S, Hachani A, Whitehead MA, Pearce WP, Berenjeno IM, Nock G, Filloux A, Beyaert R, Flamand V, Vanhaesebroeck B (2012) The p110 isoform of the kinase $\mathrm{PI}(3) \mathrm{K}$ controls the subcellular compartmentalization of TLR4 signaling and protects from endotoxic shock. Nat Immunol 13:1045-1054

107. Kagan JC, Medzhitov R (2006) Phosphoinositide-mediated adaptor recruitment controls Toll-like receptor signaling. Cell 125:943-955

108. Chiang C-Y, Veckman V, Limmer K, David M (2012) Phospholipase $C \gamma-2$ and intracellular calcium are required for lipopolysaccharide-induced Toll-like receptor 4 (TLR4) endocytosis and interferon regulatory factor 3 (IRF3) activation. J Biol Chem 287:3704-3709

109. Zanoni I, Ostuni R, Capuano G, Collini M, Caccia M, Ronchi AE, Rocchetti M, Mingozzi F, Foti M, Chirico G, Costa B, Zaza A, Ricciardi-Castagnoli P, Granucci F (2009) CD14 regulates the dendritic cell life cycle after LPS exposure through NFAT activation. Nature 460:264-268

110. Zanoni I, Ostuni R, Barresi S, Di Gioia M, Broggi A, Costa B, Marzi R, Granucci F (2012) CD14 and NFAT mediate lipopolysaccharide-induced skin edema formation in mice. J Clin Invest 122:1747-1757

111. Dunzendorfer S, Lee H-K, Soldau K, Tobias PS (2004) TLR4 is the signaling but not the lipopolysaccharide uptake receptor. J Immunol 173:1166-1170

112. Husebye H, Aune MH, Stenvik J, Samstad E, Skjeldal F, Halaas O, Nilsen NJ, Stemark H, Latz E, Lein E, Mollens TE, Bakke O, Espevik T (2010) The Rab1la GTPase controls Toll-like receptor 4-induced activation of interferon regulatory factor-3 on phagosomes. Immunity 33:583-596

113. Watanabe S, Kumazawa Y, Inoue J (2013) Liposomal lipopolysaccharide initiates TRIF-dependent signaling pathway independent of CD14. PLoS ONE 8:e60078

114. Kitchens RL, Wang P, Munford RS (1998) Bacterial lipopolysaccharide can enter monocytes via two CD14-dependent pathways. J Immunol 161:5534-5545

115. Wang Y, Yang Y, Liu X, Wang N, Cao H, Lu Y, Zhou H, Zhneg J (2012) Inhibition of clathrin/dynamin-dependent internalization interferes with LPS-mediated TRAM-TRIF-dependent signaling pathway. Cell Immunol 274:121-129 
116. Miaczynska M (2013) Effects of membrane trafficking on signaling by receptor tyrosine kinases. Cold Spring Harb Perspect Biol 5:a009035

117. Olsson S, Sundler R (2006) The role of lipid rafts in LPSinduced signaling in a macrophage cell line. Mol Immunol 43:607-612

118. Pugin J, Kravchenko VV, Lee JD, Kline L, Ulevitch RJ, Tobias PS (1998) Cell activation mediated by glycosylphosphatidylinositol-anchored or transmembrane forms of CD14. Infect Immun 66:1174-1180

119. Poussin C, Foti M, Carpentier JL, Pugin J (1998) CD14dependent endotoxin internalization via a macropinocytic pathway. J Biol Chem 273:20285-20291

120. Heit B, Kim H, Cosío G, Castano D, Collins R, Lowell CA, Kain KC, Trimble WS, Grinstein S (2013) Multimolecular signaling complexes enable Syk-mediated signaling of CD36 internalization. Dev Cell 24:372-383

121. Shang L, Daubeuf B, Triantafilou M, Olden R, Dépis F, Raby AC, Herren S, Dos Santos A, Malinge P, Dunn-Siegrist I, Benmkaddem S, Geinoz A, Magistrelli G, Rousseau F, Buatois V, Salgado-Pires S, Reith W, Monteiro R, Pugin J, Leger O, Ferlin W, Kosco-Vilbois M, Triantafilou K, Elson G (2014) Selective antibody intervention of Toll-like receptor 4 activation through Fc $\gamma$ receptor tethering. J Biol Chem 289:15309-15318

122. Rittirsch D, Flierl MA, Day DE, Nadeau BA, Zetoune FS, Sarma JV, Werner CM, Wanner GA, Simmen HP, Huber-Lang MS, Ward PA (2009) Cross-talk between TLR4 and Fc $\gamma$ receptor III (CD16) pathways. PLoS Pathog 5:e1000464

123. Horwood NJ, Mahon T, McDaid JP, Campbell J, Mano H, Brennan FM, Webster D, Foxwell BMJ (2003) Bruton's tyrosine kinase is required for lipopolysaccharide-induced tumor necrosis factor alpha production. J Exp Med 197:1603-1611

124. Krupa A, Fudala R, Florence JM, Tucker T, Allen TC, Standiford TJ, Luchowski R, Fol M, Rahman M, Gryczynski Z, Gryczynski I, Kurdowska AK (2013) Bruton's tyrosine kinase mediates Fc $\gamma$ RIIa/Toll-like receptor-4 receptor crosstalk in human neutrophils. Am J Respir Cell Mol Biol 48:240-249

125. Lin YC, Huang DY, Chu CL, Lin YL, Lin WW (2013) The tyrosine kinase Syk differentially regulates Toll-like receptor signaling downstream of the adaptor molecules TRAF6 and TRAF3. Sci Signal 6:ra71

126. Stefanova I, Corcoran ML, Horak EM, Wahl LM, Bolen JB, Horak ID (1993) Lipopolysaccharide induces activation of CD14-associated protein tyrosine kinase p53/56lyn. J Biol Chem 268:20725-20728

127. Medvedev AE, Piao W, Shoenfelt J, Rhee SH, Chen H, Basu S, Wahl LM, Fenton MJ, Vogel SN (2007) Role of TLR4 tyrosine phosphorylation in signal transduction and endotoxin tolerance. J Biol Chem 282:16042-16053

128. Smolinska MJ, Page TH, Urbaniak AM, Mutch BE, Horwood NJ (2011) Hck tyrosine kinase regulates TLR4-induced TNF and IL-6 production via AP-1. J Immunol 187:6043-6051

129. Brdicka T, Pavlistová D, Leo A, Bruyns E, Korínek V, Angelisová P, Scherer J, Shevchenko A, Hilgert I, Cerný J, Drbal K, Kuramitsu Y, Kornacker B, Horejsí V, Schraven B (2000) Phosphoprotein associated with glycosphingolipid-enriched microdomains (PAG), a novel ubiquitously expressed transmembrane adaptor protein, binds the protein tyrosine kinase Csk and is involved in regulation of $\mathrm{T}$ cell activation. $\mathrm{J}$ Exp Med 191:1591-1604

130. Beaty CD, Franklin TL, Uehara Y, Wilson CB (1994) Lipopolysaccharide-induced cytokine production in human monocytes: role of tyrosine phosphorylation in transmembrane signal transduction. Eur J Immunol 24:1278-1284

131. Smolinska MJ, Horwood NJ, Page TH, Smallie T, Foxwell BM (2008) Chemical inhibition of Src family kinases affects major
LPS-activated pathways in primary human macrophages. Mol Immunol 45:990-1000

132. Meng F, Lowell CA (1997) Lipopolysaccharide (LPS)-induced macrophage activation and signal transduction in the absence of Src-family kinases Hck, Fgr, and Lyn. J Exp Med 185:1661-1670

133. Lowell CA, Berton G (1998) Resistance to endotoxic shock and reduced neutrophil migration in mice deficient for the Src-family kinases Hck and Fgr. Proc Natl Acad Sci USA 95:7580-7584

134. Ingley E (2008) Src family kinases: regulation of their activities, levels and identification of new pathways. Biochim Biophys Acta 1784:56-65

135. English BK, Orlicek SL, Mei Z, Meals EA (1997) Bacterial LPS and IFN- $\gamma$ trigger the tyrosine phosphorylation of vav in macrophages: evidence for involvement of the hck tyrosine kinase. J Leukoc Biol 62:859-864

136. Kim JY, Lee YG, Kim MY, Byeon SE, Rhee MH, Park J, Katz DR, Chain BM, Cho JY (2010) Src-mediated regulation of inflammatory responses by actin polymerization. Biochem Pharmacol 79:431-443

137. Chen L-Y, Zuraw BL, Zhao M, Liu FT, Huang S, Pan ZK (2003) Involvement of protein tyrosine kinase in Toll-like receptor 4-mediated NF-kappa B activation in human peripheral blood monocytes. Am J Physiol Lung Cell Mol Physiol 284:L607-L613

138. Henricson BE, Carboni JM, Burkhardt AL, Vogel SN (1995) LPS and Taxol activate Lyn kinase autophosphorylation in $\mathrm{Lps}^{n}$, but not in $\mathrm{Lps}^{d}$, macrophages. Mol Med 1:428-435

139. Jiang Z, Ninomiya-Tsuji J, Qian Y, Matsumoto K, Li X (2002) Interleukin-1 (IL-1) receptor-associated kinase-dependent IL-1induced signaling complexes phosphorylate TAK1 and TAB 2 at the plasma membrane and activate TAK1 in the cytosol. Mol Cell Biol 22:7158-7167

140. Avila M, Martinez-Juarez A, Ibarra-Sanchez A, Gonzalez-Espinosa C (2012) Lyn kinase controls TLR4-dependent IKK and MAPK activation modulating the activity of TRAF-6/TAK-1 protein complex in mast cells. Innate Immun 18:648-660

141. Gong P, Angelini DJ, Yang S, Xia G, Cross AS, Mann D, Bannerman DD, Vogel SN, Goldblum SE (2008) TLR4 signaling is coupled to SRC family kinase activation, tyrosine phosphorylation of zonula adherens proteins, and opening of the paracellular pathway in human lung microvascular endothelia. J Biol Chem 283:13437-13449

142. Liu A, Gong P, Hyun SW, Wang KZ, Cates EA, Perkins D, Bannerman DD, Puché AC, Toshchakov VY, Fang S, Auron PE, Vogel SN, Goldblum SE (2012) TRAF6 protein couples Tolllike receptor 4 signaling to Src family kinase activation and opening of paracellular pathway in human lung microvascular endothelia. J Biol Chem 287:16132-16145

143. Ingley E (2012) Functions of the Lyn tyrosine kinase in health and disease. Cell Commun Signal 10:21

144. Peirce MJ, Brook M, Morrice N, Snelgrove R, Begum S, Lanfrancotti A, Notley C, Hussell T, Cope AP, Wait R (2010) Themis2/ICB1 is a signaling scaffold that selectively regulates macrophage Toll-like receptor signaling and cytokine production. PLoS ONE 5:e11465

145. Gray P, Dagvadorj J, Michelsen KS, Brikos C, Rentsendorj A, Town T, Crother TR, Arditi M (2011) Myeloid differentiation factor-2 interacts with Lyn kinase and is tyrosine phosphorylated following lipopolysaccharide-induced activation of the TLR4 signaling pathway. J Immunol 187:4331-4337

146. Xu Y, Harder KW, Huntington ND, Hibbs ML, Tarlinton DM (2005) Lyn tyrosine kinase: accentuating the positive and the negative. Immunity 22:9-18

147. Keck S, Freudenberg M, Huber M (2010) Activation of murine macrophages via TLR2 and TLR4 is negatively regulated by a 
Lyn/PI3K module and promoted by SHIP1. J Immunol 184:5809-5818

148. Brown J, Wang H, Suttles J, Graves DT, Martin M (2011) Mammalian target of rapamycin complex 2 (mTORC2) negatively regulates Toll-like receptor 4-mediated inflammatory response via FoxO1. J Biol Chem 286:44295-44305

149. Herrera-Velit P, Reiner NE (1996) Bacterial lipopolysaccharide induces the association and coordinate activation of p53/56lyn and phosphatidylinositol 3-kinase in human monocytes. J Immunol 156:1157-1165

150. Scapini P, Pereira S, Zhang H, Lowell CA (2009) Multiple roles of Lyn kinase in myeloid cell signaling and function. Immunol Rev 228:23-40

151. Wenink MH, Santegoets KC, Roelofs MF, Huijbens R, Koenen HJ, van Beek R, Joosten I, Meyer-Wentrup F, Mathsson L, Ronnelid J, Adema GJ, Bonvini E, Koenig S, van den Berg WB, van Riel PL, Radstake TR (2009) The inhibitory Fc $\gamma$ Illb receptor dampens TLR4-mediated immune responses and is selectively up-regulated on dendritic cells from rheumatoid arthritis patients with quiescent disease. J Immunol 183:4509-4520

152. Xiao W, Nishimoto H, Hong H, Kitaura J, Nunomura S, MaedaYamamoto M, Kawakami Y, Lowell CA, Ra C, Kawakami T (2005) Positive and negative regulation of mast cell activation by Lyn via the FceRI. J Immunol 175:6885-6892

153. Stewart CR, Stuart LM, Wilkinson K, van Gils JM, Deng J, Halle A, Rayner KJ, Boyer L, Zhong R, Frazier WA, Lacy-Hulbert A, El Khoury J, Golenbock DT, Moore KJ (2010) CD36 ligands promote sterile inflammation through assembly of a Toll-like receptor 4 and 6 heterodimer. Nat Immunol 11:155-161

154. van Blitterswijk WJ, van der Luit AH, Veldman RJ, Verheij M, Borst J (2003) Ceramide: second messenger or modulator of membrane structure and dynamics? Biochem 369:199-211

155. Pike LJ, Han X, Chung KN, Gross RW (2002) Lipid rafts are enriched in arachidonic acid and plasmenylethanolamine and their composition is independent of caveolin-1 expression: a quantitative electrospray ionization/mass spectrometric analysis. Biochemistry 41:2075-2088

156. Milhas D, Clarke CJ, Hannun YA (2010) Sphingomyelin metabolism at the plasma membrane: implications for bioactive sphingolipids. FEBS Lett 584:1887-1894

157. Abdel Shakor AB, Kwiatkowska K, Sobota A (2004) Cell surface ceramide generation precedes and controls Fc $\gamma$ RII clustering and phosphorylation in rafts. J Biol Chem 279:36778-36787

158. Grassmé H, Jendrossek V, Bock J, Riehle A, Gulbins E (2002) Ceramide-rich membrane rafts mediate CD40 clustering. J Immunol 168:298-307

159. Sakata A, Ochiai T, Shimeno H, Hikishima S, Yokomatsu T, Shibuya S, Toda A, Eyanagi R, Soeda S (2007) Acid sphingomyelinase inhibition suppresses lipopolysaccharide-mediated release of inflammatory cytokines from macrophages and protects against disease pathology in dextran sulphate sodiuminduced colitis in mice. Immunology 122:54-64

160. Józefowski S, Czerkies M, Łukasik A, Bielawska A, Bielawski J, Kwiatkowska K, Sobota A (2010) Ceramide and ceramide 1-phosphate are negative regulators of $\mathrm{TNF}-\alpha$ production induced by lipopolysaccharide. J Immunol 185:6960-6973

161. MacKichan ML, DeFranco AL (1999) Role of ceramide in lipopolysaccharide (LPS)-induced signaling. LPS increases ceramide rather than acting as a structural homolog. J Biol Chem 274:1767-1775

162. Schilling JD, Machkovech HM, He L, Sidhu R, Fujiwara H, Weber K, Ory DS, Schaffer JE (2013) Palmitate and lipopolysaccharide trigger synergistic ceramide production in primary macrophages. J Biol Chem 288:2923-2932

163. Medvedev AE, Blanco JC, Qureshi N, Vogel SN (1999) Limited role of ceramide in lipopolysaccharide-mediated mitogen- activated protein kinase activation, transcription factor induction, and cytokine release. J Biol Chem 274:9342-9350

164. Fischer H, Ellström P, Ekström K, Gustafsson L, Gustafsson M, Svanborg C (2007) Ceramide as a TLR4 agonist; a putative signalling intermediate between sphingolipid receptors for microbial ligands and TLR4. Cell Microbiol 9:1239-1251

165. Jin J, Zhang X, Lu Z, Perry DM, Li Y, Russo SB, Cowart LA, Hannun YA, Huang Y (2013) Acid sphingomyelinase plays a key role in palmitic acid-amplified inflammatory signaling triggered by lipopolysaccharide at low concentrations in macrophages. Am J Physiol Endocrinol Metab 305:E853-E867

166. Rozenova KA, Deevska GM, Karakashian AA, Nikolova-Karakashian MN (2010) Studies on the role of acid sphingomyelinase and ceramide in the regulation of tumor necrosis factor alpha (TNF $\alpha)$-converting enzyme activity and TNF $\alpha$ secretion in macrophages. J Biol Chem 285:21103-21113

167. Grassmé H, Jendrossek V, Riehle A, von Kürthy G, Berger J, Schwarz H, Weller M, Kolesnick R, Gulbins E (2003) Host defense against Pseudomonas aeruginosa requires ceramide-rich membrane rafts. Nat Med 9:322-330

168. Chiba N, Masuda A, Yoshikai Y, Matsuguchi T (2007) Ceramide inhibits LPS-induced production of IL-5, IL-10, and IL-13 from mast cells. J Cell Physiol 213:126-136

169. Sun Y, Fox T, Adhikary G, Kester M, Pearlman E (2008) Inhibition of corneal inflammation by liposomal delivery of short-chain, C-6 ceramide. J Leukoc Biol 83:1512-1521

170. Hailemariam TK, Huan C, Liu J, Li Z, Roman C, Kalbfeisch M, Bui HH, Peake DA, Kuo MS, Cao G, Wadgaonkar R, Jiang XC (2008) Sphingomyelin synthase 2 deficiency attenuates NFKB activation. Arterioscler Thromb Vasc Biol 28:1519-1526

171. Gowda S, Yeang C, Wadgaonkar S, Anjum F, Grinkina N, Cutaia M, Jiang XC, Wadgaonkar R (2011) Sphingomyelin synthase 2 (SMS2) deficiency attenuates LPS-induces lung injury. Am J Physiol Lung Cell Mol Physiol 300:L430-L440

172. Liu J, Huan C, Chakraborty M, Zhang H, Lu D, Kuo MS, Cao G, Jiang XC (2009) Macrophage sphingomyelin synthase 2 deficiency decreases atherosclerosis in mice. Circ Res 105:295-303

173. Yu C, Alterman M, Dobrowsky RT (2005) Ceramide displaces cholesterol from lipid rafts and decreases the association of the cholesterol binding protein caveolin-1. J Lipid Res 46:1678-1691

174. Grassme H, Jekle A, Riehle A, Schwarz H, Berger J, Sandhoff K, Kolesnick R, Gulbins E (2001) CD95 signaling via ceramiderich membrane rafts. J Biol Chem 276:20589-20596

175. Tellier E, Canault M, Rebsomen L, Bonardo B, Juhan-Vague I, Nalbone G, Peiretti F (2006) The shedding activity of ADAM17 is sequestered in lipid rafts. Exp Cell Res 312:3969-3980

176. Hsu YW, Chi KM, Huang WC, Lin WW (2001) Ceramide inhibits lipopolysaccharide-mediated nitric oxide synthase and cyclooxygenase- 2 induction in macrophages: effects on protein kinases and transcription factors. J Immunol 166:5388-5397

177. Abdel Shakor AB, Atia MM, Kwiatkowska K, Sobota A (2012) Cell surface ceramide controls translocation of transferrin receptor to clathrin-coated pits. Cell Signal 24:677-684

178. Li R, Blanchette-Mackie EJ, Ladisch S (1999) Induction of endocytic vesicles by exogenous $\mathrm{C}(6)$-ceramide. J Biol Chem 274:21121-21127

179. Reis J, Guan XQ, Kisselev AF, Papasian CJ, Qureshi AA, Morrison DC, Van Way CW 3rd, Vogel SN, Qureshi N (2011) LPS-induced formation of immunoproteasomes: TNF- $\alpha$ and nitric oxide production are regulated by altered composition of proteasome-active sites. Cell Biochem Biophys 60:77-88

180. Taylor KR, Yamasaki K, Radek KA, Di Nardo A, Goodarzi H, Golenbock D, Beutler B, Gallo RL (2007) Recognition of hyaluronan released in sterile injury involves a unique receptor complex dependent on Toll-like receptor 4, CD44, and MD-2. J Biol Chem 282:18265-18275 
181. Kawana H, Karaki H, Higashi M, Miyazaki M, Hilberg F, Kitagawa M, Harigaya K (2008) CD44 suppresses TLR-mediated inflammation. J Immunol 180:4235-4245

182. Liang J, Jiang D, Griffith J, Yu S, Fan J, Zhao X, Bucala R, Noble PW (2007) CD44 is a negative regulator of acute pulmonary inflammation and lipopolysaccharide-TLR signaling in mouse macrophages. J Immunol 178:2469-2475

183. Muto J, Yamasaki K, Taylor KR, Gallo RL (2009) Engagement of CD44 by hyaluronan suppresses TLR4 signaling and the septic response to LPS. Mol Immunol 47:449-456

184. Kim MY, Muto J, Gallo RL (2013) Hyaluronic acid oligosaccharides suppress TLR3-dependent cytokine expression in a TLR4-dependent manner. PLoS ONE 8:e72421

185. Saïd-Sadier N, Ojcius DM (2012) Alarmins, inflammasomes and immunity. Biomed J 35:437-449

186. Vega VL, Rodríguez-Silva M, Frey T, Gehrmann M, Diaz JC, Steinem C, Multhoff G, Arispe N, De Maio A (2008) Hsp70 translocates into the plasma membrane after stress and is released into the extracellular environment in a membraneassociated form that activates macrophages. $\mathrm{J}$ Immunol 180:4299-4307

187. Wang R, Kovalchin JT, Muhlenkamp P, Chandawarkar RY (2006) Exogenous heat shock protein 70 binds macrophage lipid raft microdomain and stimulates phagocytosis, processing, and MHC-II presentation of antigens. Blood 107:1636-1642

188. Tsan M-F, Gao B (2009) Heat shock proteins and immune system. J Leukoc Biol 85:905-910

189. Aneja R, Odoms K, Dunsmore K, Shanley TP, Wong HR (2006) Extracellular heat shock protein-70 induces endotoxin tolerance in THP-1 cells. J Immunol 177:7184-7192

190. Triantafilou M, Triantafilou K (2004) Heat-shock protein 70 and heat-shock protein 90 associate with Toll-like receptor 4 in response to bacterial lipopolysaccharide. Biochem Soc Trans 32:636-639

191. Gupta A, Cooper ZA, Tulapurkar ME, Potla R, Maity T, Hasday JD, Singh IS (2013) Toll-like receptor agonists and febrile range hyperthermia synergize to induce heat shock protein 70 expression and extracellular release. J Biol Chem 288:2756-2766

192. Nozaki S, Kashiwagi H, Yamashita S, Nakagawa T, Kostner B, Tomiyama Y, Nakata A, Ishigami M, Miyagawa J, KamedaTakemura K, Kurata Y, Matsuzawa Y (1995) Reduced uptake of oxidized low density lipoproteins in monocyte-derived macrophages from CD36-deficient subjects. J Clin Invest 96:1859-1865

193. Chavez-Sanchez L, Garza-Reyes MG, Espinosa-Luna JE, Chavez-Rueda K, Legorreta-Haquet MV, Blanco-Favela F (2014) The role of TLR2, TLR4 and CD36 in macrophage activation and foam cell formation in response to oxLDL in humans. Hum Immunol 75:322-329
194. Stuart LM, Deng J, Silver JM, Takahashi K, Tseng AA, Hennessy EJ, Ezekowitz RA, Moore KJ (2005) Response to Staphylococcus aureus requires CD36-mediated phagocytosis triggered by the $\mathrm{COOH}$-terminal cytoplasmic domain. J Cell Biol 170:477-485

195. Baranova IN, Kurlander R, Bocharov AV, Vishnyakova TG, Chen Z, Remaley AT, Csako G, Patterson AP, Eggerman TL (2008) Role of human CD36 in bacterial recognition, phagocytosis, and pathogen-induced JNK-mediated signaling. J Immunol 181:7147-7156

196. Kannan Y, Sundaram K, Aluganti Narasimhulu C, Parthasarathy S, Wewers MD (2012) Oxidatively modified low density lipoprotein (LDL) inhibits TLR2 and TLR4 cytokine responses in human monocytes but not in macrophages. J BiolChem 287:23479-23488

197. Triantafilou M, Gamper FGJ, Haston RM, Mouratis MA, Morath S, Hartung T, Triantafilou K (2006) Membrane sorting of Tolllike receptor (TLR)-2/6 and TLR2/1 heterodimers at the cell surface determines heterotypic associations with CD36 and intracellular targeting. J Biol Chem 281:31002-31011

198. Triantafilou M, Gamper FGJ, Lepper PM, Mouratis MA, Schumann C, Harokopakis E, Schifferle RE, Hajishengallis G, Triantafilou K (2007) Lipopolysaccharides from atherosclerosisassociated bacteria antagonize TLR4, induce formation of TLR2/1/CD36 complexes in lipid rafts and trigger TLR2induced inflammatory responses in human vascular endothelial cells. Cell Microbiol 9:2030-2039

199. Bzowska M, Nogieć A, Skrzeczyńska-Moncznik J, Mickowska B, Guzik K, Pryjma J (2012) Oxidized LDLs inhibit TLRinduced IL-10 production by monocytes: a new aspect of pathogen-accelerated atherosclerosis. Inflammation 35:15671584

200. Fessler MB, Arndt PG, Frasch SC, Lieber JG, Johnson CA, Murphy RC, Nick JA, Bratton DL, Malcolm KC, Worthen GS (2004) Lipid rafts regulate lipopolysaccharide-induced activation of $\mathrm{Cdc} 42$ and inflammatory functions of the human neutrophil. J Biol Chem 279:39989-39998

201. Suzuki M, Tachibana I, Takeda Y, He P, Minami S, Iwasaki T, Kida H, Goya S, Kijima T, Yoshida M, Kumagai T, Osaki T, Kawase I (2009) Tetraspanin CD9 negatively regulates lipopolysaccharide-induced macrophage activation and lung inflammation. J Immunol 182:6485-6493

202. Zhu X, Lee JY, Timmins JM, Brown JM, Boudyguina E, Mulya A, Gebre AK, Willingham MC, Hiltbold EM, Mishra N, Maeda N, Parks JS (2008) Increased cellular free cholesterol in macrophage-specific Abca1 knock-out mice enhances proinflammatory response. J Biol Chem 283:22930-22941 